\title{
Static and Time-Resolved Spectroscopic Studies of Low-Symmetry Ru(II) Polypyridyl Complexes
}

\author{
Aimee E. Curtright and James K. McCusker* \\ Department of Chemistry, University of California at Berkeley, Berkeley, California 94720-1460
}

Received: June 14, 1999; In Final Form: July 9, 1999

\begin{abstract}
The spectroscopic and electrochemical properties of a series of four $\mathrm{Ru}^{\mathrm{II}}$ polypyridyl complexes are reported. Compounds of the form $\left[\mathrm{Ru}(\mathrm{dmb})_{x}(\mathrm{dea})_{3-x}\right]^{2+}(x=0-3)$, where dmb is $4,4^{\prime}$-dimethyl-2,2'-bipyridine and dea is $4,4^{\prime}$-bis(diethylamino)-2,2'-bipyridine, have been prepared and studied using static and time-resolved electronic and vibrational spectroscopies as a prelude to femtosecond spectroscopic studies of excited-state dynamics. Static electronic spectra in $\mathrm{CH}_{3} \mathrm{CN}$ solution reveal a systematic shift of the MLCT absorption envelope from a maximum of $458 \mathrm{~nm}$ in the case of $\left[\mathrm{Ru}(\mathrm{dmb})_{3}\right]^{2+}$ to $518 \mathrm{~nm}$ for $\left[\mathrm{Ru}(\mathrm{dea})_{3}\right]^{2+}$ with successive substitutions of dea for dmb, suggesting a dea-based chromophore as the lowest-energy species. However, analysis of static and time-resolved emission data indicates an energy gap ordering of $\left[\mathrm{Ru}(\mathrm{dmb})_{3}\right]^{2+}>[\mathrm{Ru}-$ $\left.(\mathrm{dmb})_{2}(\mathrm{dea})\right]^{2+}>\left[\mathrm{Ru}(\mathrm{dea})_{3}\right]^{2+}>\left[\mathrm{Ru}(\mathrm{dmb})(\mathrm{dea})_{2}\right]^{2+}$, at variance with the electronic structures inferred from the absorption spectra. Nanosecond time-resolved electronic absorption and time-resolved step-scan infrared data are used to resolve this apparent conflict and confirm localization of the long-lived ${ }^{3}$ MLCT state on dmb in all three complexes where this ligand is present, thus making the dea-based excited state unique to [Ru$\left.(\text { dea })_{3}\right]^{2+}$. Electrochemical studies further reveal the origin of this result, where a strong influence of the dea ligand on the oxidative $\mathrm{Ru}^{\mathrm{II} / I I I}$ couple, due to $\pi$ donation from the diethylamino substituent, is observed. The electronic absorption spectra are then reexamined in light of the now well-determined excited-state electronic structure. The results serve to underscore the importance of complete characterization of the electronic structures of transition metal complexes before embarking on ultrafast studies of their excited-state properties.
\end{abstract}

\section{Introduction}

The study of the photoinduced properties of ruthenium polypyridyl complexes has proven useful both for furthering the understanding of energy- and electron-transfer processes ${ }^{1-3}$ and in the development of applied photoconversion systems. ${ }^{4-7}$ The process of interest in these complexes is most often the metal-to-ligand charge transfer (MLCT) transition, in which a formal oxidation of the metal and reduction of the ligand occurs upon photoexcitation, e.g. for $\left[\mathrm{Ru}(\mathrm{bpy})_{3}\right]^{2+}$

$$
\left[\mathrm{Ru}^{\mathrm{II}}(\mathrm{bpy})_{3}\right]^{2+} \stackrel{h v}{\longrightarrow}\left[\mathrm{Ru}^{\mathrm{III}}\left(\mathrm{bpy}{ }^{\bullet-}\right)(\mathrm{bpy})_{2}\right]^{2+}
$$

where bpy is $2,2^{\prime}$-bipyridine. One particularly attractive feature of this class of molecules is the tunability of the MLCT chromophore. The large body of knowledge concerning synthetic methodologies for preparing these complexes, coupled with a detailed understanding of their electronic structure, now enables predictable synthetic modulation of photophysical properties. ${ }^{1,8,9}$ This potential for tunability has been most clearly demonstrated with bis- ${ }^{1,10-15}$ and tris-heteroleptic complexes, ${ }^{16-19}$ in which two or three different ligands are incorporated into a single compound to create broadened MLCT bands. Asymmetric complexes have found use in photovoltaic systems, for example, wherein broadening of the MLCT absorption envelope holds promise for increased absorptive cross sections and thus a more efficient use of the solar spectrum for photoelectric conversion.

Solution studies of mixed-ligand complexes of this type strongly suggest that the photoexcited electron is localized on the lowest energy ligand, at least on long ( $>$ nanosecond) time scales. ${ }^{20-24}$ However, the relaxation processes leading to the formation of this state are not well understood. To this end, we have recently shown that excited-state evolution in $\left[\mathrm{Ru}(\mathrm{bpy})_{3}\right]^{2+}$ occurs on a time scale of ca. $100 \mathrm{fs},{ }^{25}$ illustrating the important role ultrafast spectroscopy can play in enhancing our understanding of such fundamental physical processes. This observation takes on greater significance when combined with the recent work of Ellingson et al. ${ }^{26}$ and others ${ }^{27-29}$ indicating a comparable time scale for electron injection from $\mathrm{Ru}$-based chromophores into $\mathrm{TiO}_{2}$. The ultrafast spectroscopy of low-symmetry complexes is therefore of interest not only for addressing fundamental questions regarding excited-state relaxation mechanisms but also for understanding and ultimately manipulating excited-state dynamics in molecular assemblies employing these types of complexes as photosensitizers.

Critical to the interpretation of the femtosecond spectroscopy of transition metal complexes is a detailed understanding of their excited-state electronic structures, in terms of both the FranckCondon state and lower-lying electronic states. In this paper, we report a study of a series of four complexes containing two substituted bipyridines, 4,4'-dimethyl-2,2'-bipyridine (dmb) and 4,4'-bis(diethylamino)-2,2'-bipyridine (dea). We expect that
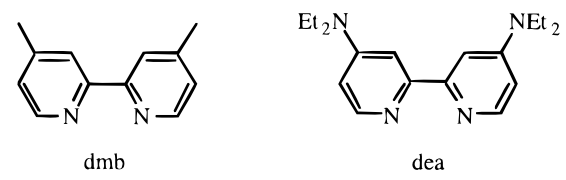

these mixed-ligand complexes, which contain energetically wellseparated MLCT manifolds, will provide insight into excitedstate relaxation processes unique to asymmetric transition metal complexes. Herein we focus on the static and nanosecond 
time-scale characterization of these compounds. We believe the results we have obtained, in addition to providing the necessary starting point for future ultrafast work on these compounds, also serve to underscore the importance of static and long time-scale characterization of transition metal chromophores as a prerequisite for femtosecond studies of their excited-state dynamics.

\section{Experimental Section}

General. All commercial reagents and materials were used as received. Solvents were purchased from Fisher or Aldrich Chemical Co., the ligands 2,2'-bipyridine (bpy) and 4,4'dimethyl-2,2'-bipyridine (dmb) from Aldrich, and $\mathrm{RuCl}_{3} \cdot x \mathrm{H}_{2} \mathrm{O}$ from Strem Chemicals, Inc. Basic alumina for column chromatography was obtained from Fisher (Brockman Activity I). Syntheses of metal complexes were performed under argon. NMR spectra were obtained on either a Bruker AMX 300 (300 $\mathrm{MHz})$ or AMX $400(400 \mathrm{MHz})$ and referenced to solvent signals as internal standards. Elemental analyses and mass spectra were performed by the Analytical Facilities of the University of California at Berkeley. Mass spectra were obtained by electrospray for metal complexes and FAB for the dea ligand. All spectra agreed with simulations; however, relative intensities of the observed metal complex fragments varied with solvent and experimental conditions. Typical mass-to-charge ratios $(\mathrm{m} /$ z) and intensities are reported below.

Synthesis of Ruthenium Complexes. $\mathrm{Ru}(\mathrm{DMSO})_{4} \mathrm{Cl}_{2}$ was prepared by a previously published method ${ }^{30}$ and used as a starting material for the synthesis of $\left[\mathrm{Ru}(\mathrm{dmb})_{3}\right]^{2+},\left[\mathrm{Ru}(\mathrm{dea})_{3}\right]^{2+}$, and $\left[\mathrm{Ru}(\mathrm{dmb})_{2}(\mathrm{dea})\right]^{2+}$. The synthesis of $\left[\mathrm{Ru}(\mathrm{dmb})_{3}\right]^{2+}$ has been reported. ${ }^{31}$ The ligand 4,4'-bis(diethylamino)-2,2'-bipyridine (dea) was prepared by a previously published method. ${ }^{32}$

Tris(4,4'-bis(diethylamino)-2,2' -bipyridine)ruthenium(II) Hexafluorophosphate, $\left[\mathbf{R u}(\mathbf{d e a})_{3}\right]\left(\mathbf{P F}_{6}\right)_{2}$. A solution of $\mathrm{Ru}-$ (DMSO) ${ }_{4} \mathrm{Cl}_{2}(24 \mathrm{mg}, 0.050 \mathrm{mmol})$ and dea (49 mg, $\left.0.16 \mathrm{mmol}\right)$ were refluxed for $24 \mathrm{~h}$, protected from light, in $10 \mathrm{~mL}$ of $100 \%$ ethanol. After the solution was allowed to cool to room temperature, the solvent was removed and the resulting solid dissolved in water. Addition of $\mathrm{NH}_{4} \mathrm{PF}_{6}(81 \mathrm{mg}, 0.50 \mathrm{mmol})$ yielded the $\mathrm{PF}_{6}{ }^{-}$salt as a red solid. The complex was filtered and rinsed with water and then ether. Subsequent treatment with reductant and purification/recrystallization under inert atmosphere were necessary due to the facile oxidation of $\mathrm{Ru}$ in deacontaining complexes. The product was redissolved in a small amount of $\mathrm{CH}_{3} \mathrm{CN}$, and approximately $0.5 \mathrm{~mL}$ of triethylamine was added to this solution to ensure the +2 oxidation state of the metal and the deprotonation of the diethylamino groups of dea. Column chromatography on basic alumina with 1:3 acetonitrile/toluene as an eluent was performed inside an argonfilled glovebox. The desired complex eluted as a red band; $\mathrm{Ru}^{\mathrm{III}}$ species (green in color) remained on the column. The complex was allowed to recrystallize by slow evaporation of acetonitrile from the eluent mixture inside the glovebox. Anal. Calc. for $\mathrm{C}_{54} \mathrm{H}_{78} \mathrm{~N}_{12} \mathrm{RuP}_{2} \mathrm{~F}_{12} \cdot 1 /{ }_{2} \mathrm{C}_{7} \mathrm{H}_{8}$ : C, 51.84; H, 6.20; N, 12.62. Found: C, 51.60; H, 6.46; N, 12.18. MS(ES): $\mathrm{m} / \mathrm{z} 1142$ ([M$\left.\left.\mathrm{PF}_{6}\right]^{+}, 70 \%\right) ; m / z 498\left(\left[\mathrm{M}-2 \mathrm{PF}_{6}\right]^{2+}, 100 \%\right)$.

Bis(4,4'-dimethyl-2,2'-bipyridine)(4,4'-bis(diethylamino)2,2'-bipyridine) ruthenium(II) Hexafluorophosphate, [Ru$\left.(\mathbf{d m b})_{2}(\mathbf{d e a})\right]\left(\mathbf{P F}_{\mathbf{6}}\right)_{2}$. This compound was prepared from $\mathrm{Ru}-$ $(\mathrm{dmb})_{2}(\mathrm{ox})$ in the following manner:

(a) Bis(4,4'-dimethyl-2,2'-bipyridine)ruthenium(II) Oxalate, $\mathrm{Ru}(\mathrm{dmb})_{2}(o x) . \mathrm{Ru}(\mathrm{dmb})_{2} \mathrm{Cl}_{2}$ was prepared from $\mathrm{Ru}(\mathrm{DMSO})_{4} \mathrm{Cl}_{2}$ by a previously reported method. ${ }^{11,31}$ The crude solid product, including the excess $\mathrm{LiCl}$ present in the reaction mixture, was dissolved in water and heated to ensure complete dissolution.
Five equivalents of oxalic acid was added to the solution, which was then refluxed overnight. The resulting precipitate was filtered off and rinsed with copious quantities of water, followed by ether. The yield was $60 \%$ based on the $\mathrm{Ru}(\mathrm{DMSO})_{4} \mathrm{Cl}_{2}$ starting material. Anal. Calc. for $\mathrm{C}_{26} \mathrm{H}_{24} \mathrm{~N}_{4} \mathrm{O}_{4} \mathrm{Ru} \cdot 2 \mathrm{H}_{2} \mathrm{O}$ : C, 52.61; H, 4.75; N, 9.44. Found: C, 51.35; H, 4.72; N, 9.28. As product was precipitated from a 50 -fold excess $\mathrm{LiCl}$ solution, trace amounts of $\mathrm{LiCl}$ most likely account for the consistently low values. $\mathrm{MS}(\mathrm{ES}): \mathrm{m} / \mathrm{z} 559\left([\mathrm{M}+\mathrm{H}]^{+}, 100 \%\right) . \mathrm{m} / \mathrm{z} 581$ $\left([\mathrm{M}+\mathrm{Na}]^{+}, 30 \%\right)$.

(b) $\left[R u(d m b)_{2}(d e a)\right]\left(P F_{6}\right)_{2} . R u(d m b)_{2}(\mathrm{ox})$ (27 mg, 0.048 mmol) was dissolved in $\mathrm{MeOH}$ and heated slightly to facilitate dissolution of the solid. After the solution was allowed to cool, 2 equiv of dea $(29 \mathrm{mg}, 0.097 \mathrm{mmol})$ was added, followed by $\sim 60$ equiv of $\mathrm{HCl}$ (as $12 \mathrm{M} \mathrm{HCl}$ ). The reaction mixture was protected from light and stirred overnight at room temperature. The solvent was removed by rotary evaporation and the resulting solid dissolved in $\mathrm{CH}_{2} \mathrm{Cl}_{2}$. The product was then extracted into $\mathrm{H}_{2} \mathrm{O}$, and addition of $\mathrm{NH}_{4} \mathrm{PF}_{6}(39 \mathrm{mg}, 0.24 \mathrm{mmol})$ resulted in precipitation of the $\mathrm{PF}_{6}{ }^{-}$salt, which was filtered, rinsed with water and ether, and then redissolved in acetonitrile. The solution was loaded onto a basic alumina column under inert atmosphere and eluted with 1:3 acetonitrile/toluene. The final product was obtained by slow evaporation of this eluent. Elemental analysis was unsatisfactory, but ${ }^{1} \mathrm{H}$ NMR and mass spectral analysis, as well as electrochemical data, confirmed the identity of the desired complex. ${ }^{1} \mathrm{H}$ NMR $\left(\mathrm{C}_{3} \mathrm{D}_{6} \mathrm{O}\right): 1.19(\mathrm{t}, 6 \mathrm{H}), 2.55$ (s, 3H), $2.58(\mathrm{~s}, 3 \mathrm{H}), 3.58(\mathrm{q}, 4 \mathrm{H}), 6.71(\mathrm{dd}, 1 \mathrm{H}), 7.23(\mathrm{~d}, 1 \mathrm{H}), 7.34(\mathrm{~d}$, $1 \mathrm{H}), 7.43(\mathrm{~d}, 1 \mathrm{H}), 7.72,(\mathrm{~d}, 1 \mathrm{H}), 7.80(\mathrm{~d}, 1 \mathrm{H}), 7.97(\mathrm{~d}, 1 \mathrm{H})$, 8.64 (s, 2H). MS(ES): $m / z 913\left(\left[\mathrm{M}_{-} \mathrm{PF}_{6}\right]^{+}, 85 \%\right) . \mathrm{m} / \mathrm{z} 384$ ([M$\left.\left.2 \mathrm{PF}_{6}\right]^{2+}, 100 \%\right)$.

Bis $\left(4,4^{\prime}\right.$-bis(diethylamino)-2, $2^{\prime}$-bipyridine $)\left(4,4^{\prime}\right.$-dimethyl2,2'-bipyridine) ruthenium(II) Hexafluorophosphate, [Ru$\left.(\mathbf{d e a})_{2}(\mathbf{d m b})\right]\left(\mathbf{P F}_{\mathbf{6}}\right)_{2}$. This complex was prepared following a literature method for the synthesis of $\left[\mathrm{Ru}(\mathrm{dea})_{2}(\mathrm{bpy})\right]^{2+} .^{32} \mathrm{Due}$ to the low potential of the $\mathrm{Ru}^{\mathrm{II} / \mathrm{III}}$ couple, the final alumina column was run inside an Ar-filled glovebox, and the fractions containing the desired product were allowed to recrystallize by slow evaporation of acetonitrile from toluene in this same inert environment. Anal. Calc for $\mathrm{C}_{48} \mathrm{H}_{64} \mathrm{~N}_{10} \mathrm{RuP}_{2} \mathrm{~F}_{12} \cdot{ }_{1}{ }_{2} \mathrm{C}_{7} \mathrm{H}_{8}$ : C, 50.78; H, 5.63; N, 11.50. Found: C, 50.65; H, 4.98; N, 11.07. $\mathrm{MS}(\mathrm{ES}): m / z, 1028\left(\left[\mathrm{M}-\mathrm{PF}_{6}\right]^{+}, 35 \%\right) \cdot m / z 441\left(\left[\mathrm{M}-2 \mathrm{PF}_{6}\right]^{2+}\right.$, $50 \%)$.

\section{Physical Measurements}

Cyclic Voltammetry. Electrochemical measurements were performed using a BAS CV-50W voltammetric analyzer. A standard three-electrode setup was used, consisting of a $\mathrm{Pt}$ working electrode, a Pt wire counter electrode, and a Ag/Ag$\left(\mathrm{NO}_{3}\right)$ reference electrode. Potentials are presented vs SCE by adding $273 \mathrm{mV}$ to the values obtained vs $\mathrm{Ag} / \mathrm{Ag}\left(\mathrm{NO}_{3}\right)$. Compounds were dissolved in distilled $\mathrm{CH}_{3} \mathrm{CN}$ with $0.1 \mathrm{M}$ tetrabutylammonium hexafluorophosphate as the supporting electrolyte. Measurements were performed inside an Ar-filled glovebox. All complexes showed reversible oxidation waves $\left(\mathrm{Ru}^{\mathrm{II} / \mathrm{III}}\right)$ over several consecutive scans. In the case of $\left[\mathrm{Ru}(\mathrm{dea})_{3}\right]$ $\left(\mathrm{PF}_{6}\right)_{2}$, the second and third reductive waves were found to be irreversible, but all other complexes showed three reversible reduction waves over multiple scans.

Static Absorption and Emission Spectra. All spectroscopic data were obtained in distilled, deoxygenated $\mathrm{CH}_{3} \mathrm{CN}$, with the sealed samples prepared inside an Ar-filled glovebox. Absorption spectra were obtained on a Hewlett-Packard HP8452A diode array spectrometer and are accurate to $\pm 2 \mathrm{~nm}$. Steady- 
state emission spectra were measured on a Spex Fluorolog fluorimeter and have been corrected for wavelength dependence of the source, emission monochromator, and PMT. Spectra were fit to determine energy gap values $\left(E_{0}\right)$ as described elsewhere. ${ }^{31,33,34}$ Radiative quantum yield measurements were made on dilute solutions $(\mathrm{OD} \sim 0.1)$ and are reported relative to [Os(bpy $\left.)_{3}\right]\left(\mathrm{PF}_{6}\right)_{2}(0.005 \pm 10 \%) .{ }^{35}$ Values for $\phi_{\mathrm{em}}, k_{\mathrm{nr}}$, and $k_{\mathrm{r}}$ were calculated as previously described. ${ }^{31}$

Nanosecond Time-Resolved Emission and Absorption. Instrumentation used for obtaining nanosecond time-resolved data has been described elsewhere. ${ }^{31}$ Excited-state difference absorption spectra were obtained with constant laser excitation power ( $\sim 3 \mathrm{~mJ}$ at $480 \mathrm{~nm}$ ) and pump-probe cross section, and were normalized for sample absorbance at the excitation wavelength for comparative purposes. The $\Delta \mathrm{OD}$ values at the bleach minimum were very similar $(\sim 0.11)$, and the spectra presented below are normalized to one at this minimum for comparison of energetic trends.

Static and Nanosecond Step-Scan FTIR. All measurements were performed on a Bruker model IFS88 spectrometer at a spectral resolution of $4 \mathrm{~cm}^{-1} . \mathrm{CD}_{3} \mathrm{CN}$ (Cambridge Isotope Labs) and a CaF-sealed cell (Spectratech, $0.2 \mathrm{~mm}$ path length) provided the appropriate spectral window. The details of the step-scan experimental setup and procedure for the calculation of excited-state difference spectra have been described previously. ${ }^{36}$ The Nd:YAG laser excitation source, operated at 355 $\mathrm{nm}$ for $\left[\mathrm{Ru}(\mathrm{dmb})_{3}\right]^{2+}$ excitation and $532 \mathrm{~nm}$ for the three other complexes, is also described in this reference. Typical pump energies were 5-10 mJ per pulse. Each reported excited-state difference spectrum is an average of 26-28 scans, performed with several sample changes while monitoring the ground-state spectrum every 3-4 scans to ensure the integrity of the sample. For each scan, folding limits of 2250 and $1130 \mathrm{~cm}^{-1}$ resulted in 570 mirror positions, and 30 laser-induced decays were averaged at each position. Sampling intervals were $25 \mathrm{~ns}$; data presented herein correspond to the average of a single $25 \mathrm{~ns}$ time slice.

Spectroelectrochemical Measurements. UV-vis spectroelectrochemical measurements were performed on a HewlettPackard HP8452A modified with a home-built optical electrochemical cell based on a previously published design. ${ }^{37}$ Oxidative measurements were reversible and difference spectra are reported after approximately $20 \mathrm{~min}$ at a potential $100 \mathrm{mV}$ more positive (more oxidizing) than the $E_{1 / 2}{ }^{\text {ox }}$. However, reductive spectra exhibit drifting isosbestic points after several minutes, even at a potential at or less negative (less reducing) than the $E_{1 / 2}$ for the first reductive wave. The spectra reported, therefore, were obtained before this change, after $2-5 \mathrm{~min}$ at the reducing potential. For reductive runs, the sample cell was filled and assembled inside an Ar glovebox and immediately placed into a $\mathrm{N}_{2}$ purged optical compartment to minimize these problems. For infrared spectroelectrochemistry, the Bruker model IFS88 spectrometer was interfaced to an ATR device (ASI Applied Systems Durasampl $I R$, with $3 \mathrm{~mm}$ diamond window and KRS-5 support element) and a home-built electrochemical cell. ${ }^{38}$ Oxidative scans yielded the expected difference spectra for ferrocene conversion to the ferrocenium cation ${ }^{39,40}$ for both the electronic absorption and infrared measurements.

\section{Results and Discussion}

We have synthesized a series of four complexes across which the dmb and dea ligand content is systematically varied: [Ru$\left.(\mathrm{dmb})_{3}\right]^{2+},\left[\mathrm{Ru}(\mathrm{dmb})_{2}(\mathrm{dea})\right]^{2+},\left[\operatorname{Ru}(\mathrm{dea})_{2}(\mathrm{dmb})\right]^{2+}$, and $[\mathrm{Ru}-$ $\left.(\mathrm{dea})_{3}\right]^{2+}$. Our intent was to thoroughly characterize the
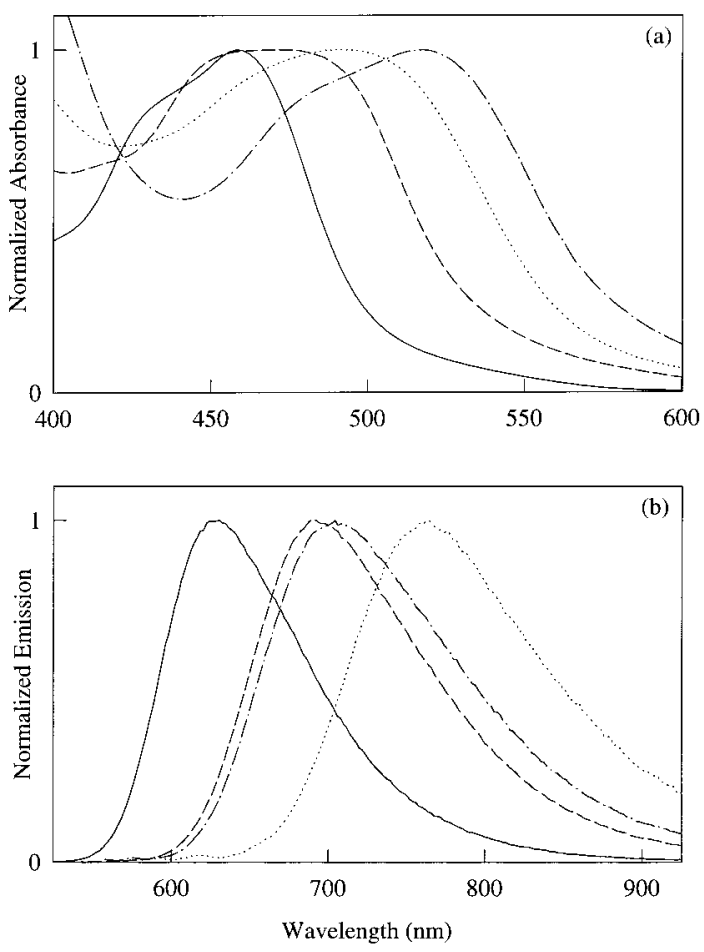

Figure 1. (a) Absorption spectra of $\left[\mathrm{Ru}(\mathrm{dmb})_{3}\right]\left(\mathrm{PF}_{6}\right)_{2}$ (solid), $[\mathrm{Ru}-$ $\left.(\mathrm{dmb})_{2}(\mathrm{dea})\right]\left(\mathrm{PF}_{6}\right)_{2}$ (dash), $\left[\mathrm{Ru}(\mathrm{dea})_{2}(\mathrm{dmb})\right]\left(\mathrm{PF}_{6}\right)_{2}(\mathrm{dot})$, and $\left[\mathrm{Ru}(\mathrm{dea})_{3}\right]$ $\left(\mathrm{PF}_{6}\right)_{2}$ (dash-dot) in deoxygenated $\mathrm{CH}_{3} \mathrm{CN}$ at $298 \mathrm{~K}$. (b) Corrected emission spectra of $\left[\mathrm{Ru}(\mathrm{dmb})_{3}\right]\left(\mathrm{PF}_{6}\right)_{2}$ (solid), $\left[\mathrm{Ru}(\mathrm{dmb})_{2}(\mathrm{dea})\right]\left(\mathrm{PF}_{6}\right)_{2}$ (dash), $\left[\mathrm{Ru}(\mathrm{dea})_{2}(\mathrm{dmb})\right]\left(\mathrm{PF}_{6}\right)_{2}(\mathrm{dot})$, and $\left[\mathrm{Ru}(\mathrm{dea})_{3}\right]\left(\mathrm{PF}_{6}\right)_{2}$ (dash-dot) in deoxygenated $\mathrm{CH}_{3} \mathrm{CN}$ at $298 \mathrm{~K}$. Excitation was performed at the $\lambda_{\text {abs max }}$ (Table 1) of each compound.

electronic structure of these complexes as a prelude to studies of their femtosecond excited-state dynamics. The protocols for characterizing the electronic structure of compounds in this class are now well established and include a range of static and timeresolved electronic and vibrational spectroscopies. In most cases, inferences about excited-state ordering from absorption spectra are borne out through these other spectroscopies. However, this is not the case with the present series. While the absorption and emission data presented below appear at first to be in conflict, when combined with nanosecond transient absorption and electrochemical data it will be shown that the apparent inconsistency can be understood to obtain a cohesive description of the electronic structures of these compounds.

Static Absorption Spectra. The ground-state absorption spectra for all four compounds are shown in Figure 1a; values for $\lambda_{\text {abs max }}$ are given in Table 1 . The absorption maxima of the lowest energy MLCT bands of the two tris complexes in this study, $\left[\mathrm{Ru}(\mathrm{dmb})_{3}\right]^{2+}(458 \mathrm{~nm})$ and $\left[\mathrm{Ru}(\mathrm{dea})_{3}\right]^{2+}(518 \mathrm{~nm})$, are separated by $\sim 2500 \mathrm{~cm}^{-1}$. This is a relatively large energetic separation for molecules in this class, ${ }^{1}$ and thus motivated our selection of these ligands. In accord with previous observations for bis-heteroleptic complexes, it was expected that incorporation of both ligands into a single complex would result in a broadened absorption band composed of two distinct, wellseparated MLCT manifolds. Indeed, the absorption maxima across the series are observed to shift to longer wavelengths with increasing dea content, with the MLCT absorption maxima of the mixed ligand complexes falling between those of the two tris complexes at 472 and $488 \mathrm{~nm}$, respectively. A qualitative examination of the band shape also follows logically: the spectra have a gradual build-in of intensity on the low-energy shoulder of the MLCT envelope with increasing dea content. This is 
TABLE 1: Photophysical Data of the dmb/dea Series in Deoxygenated $\mathrm{CH}_{3} \mathrm{CN}$ at $298 \mathrm{~K}$

\begin{tabular}{lcccrcc}
\hline \multicolumn{1}{c}{ complex } & $\lambda_{\text {abs max }}(\mathrm{nm})$ & $\lambda_{\mathrm{em} \max }(\mathrm{nm})$ & $\phi_{\mathrm{em}}\left(\times 10^{-3}\right)$ & \multicolumn{1}{c}{$\tau(\mathrm{ns})^{a}$} & $k_{\mathrm{r}}\left(\times 10^{4} \mathrm{~s}^{-1}\right)^{b}$ & $k_{\mathrm{nr}}\left(\times 10^{6} \mathrm{~s}^{-1}\right)^{b}$ \\
\hline$\left[\mathrm{Ru}(\mathrm{dmb})_{3}\right]\left(\mathrm{PF}_{6}\right)_{2}$ & 458 & 630 & $73 \pm 6^{c}$ & $887 \pm 9$ & $8.23 \pm 0.68$ & $1.05 \pm 0.013$ \\
{$\left[\mathrm{Ru}(\mathrm{dmb})_{2}(\mathrm{dea})\right]\left(\mathrm{PF}_{6}\right)_{2}$} & 472 & 690 & $8.3 \pm 0.8^{d}$ & $177 \pm 5$ & $4.69 \pm 0.49$ & $5.70 \pm 0.16$ \\
{$\left[\mathrm{Ru}(\mathrm{dea})_{2}\left(\mathrm{dmb}_{2}\right]\left(\mathrm{PF}_{6}\right)_{2}\right.$} & 488 & 762 & $1.3 \pm 0.1^{d}$ & $28 \pm 3$ & $4.64 \pm 0.49$ & $35.7 \pm 1.28$ \\
{$\left[\mathrm{Ru}(\mathrm{dea})_{3}\right]\left(\mathrm{PF}_{6}\right)_{2}$} & 518 & 704 & $3.6 \pm 0.4^{d}$ & $75 \pm 5$ & $4.80 \pm 0.58$ & $13.3 \pm 0.89$
\end{tabular}

${ }^{a}$ The relative uncertainty is reported as $2 \sigma$, based on the standard deviation of three measurements. ${ }^{b}$ Error bars are based on propagation of error from $\phi_{\mathrm{em}}$ and $\tau .{ }^{c}$ Value taken from ref $31 .{ }^{d}$ Error bars are based on the $10 \%$ uncertainty in $\left[\mathrm{Os}(\mathrm{bpy})_{3}\right]^{2+}$ quantum yield reference value. ${ }^{35}$

TABLE 2: Energy Gap Values $\left(E_{0}\right)$, Electrochemical Data $\left(E_{1 / 2}{ }^{\mathrm{ox}}\right.$ and $\left.E_{1 / 2}{ }^{\mathrm{red}}\right),{ }^{a}$ and $D^{\prime}$ Values for the dmb/dea Series in CH $\mathrm{CHN}_{3}$

\begin{tabular}{lcccccccc}
\hline \multicolumn{1}{c}{ complex } & $E_{0}\left(\mathrm{~cm}^{-1}\right)$ & $E_{1 / 2}{ }^{\text {ox }}$ & $E_{1 / 2}{ }^{\text {red1 }}$ & $E_{1 / 2}{ }^{\text {red2 }}$ & $E_{1 / 2}^{\text {red3 }}$ & $\Delta \mathbf{E}_{1 / 2}(\mathrm{~V})^{b}$ & $\Delta E_{1 / 2}\left(\mathrm{~cm}^{-1}\right)^{b}$ & $D^{\prime}\left(\mathrm{cm}^{-1}\right)^{c}$ \\
\hline$\left[\mathrm{Ru}(\mathrm{dmb})_{3}\right]\left(\mathrm{PF}_{6}\right)_{2}$ & 16100 & +1.08 & -1.49 & -1.68 & -1.93 & 2.57 & 20700 \\
{$\left[\mathrm{Ru}(\mathrm{dmb})_{2}(\mathrm{dea})\right]\left(\mathrm{PF}_{6}\right)_{2}$} & 14600 & +0.769 & -1.57 & -1.78 & -2.15 & 2.34 & 18800 \\
{$\left[\mathrm{Ru}(\mathrm{dea})_{2}(\mathrm{dmb})\right]\left(\mathrm{PF}_{6}\right)_{2}$} & 13300 & +0.533 & -1.66 & -2.01 & -2.19 & 2.19 & 17600 \\
{$\left[\mathrm{Ru}(\mathrm{dea})_{3}\right]\left(\mathrm{PF}_{6}\right)_{2}$} & 14400 & +0.286 & -1.90 & $d$ & $d$ & 2.19 & 17600
\end{tabular}

${ }^{a}$ Electrochemical potentials are in $\mathrm{V}$ vs SCE collected at a scan rate of $100 \mathrm{mV} \mathrm{s}{ }^{-1} \cdot{ }^{b} \Delta E_{1 / 2}=E_{1 / 2}{ }^{\mathrm{ox}}-E_{1 / 2}{ }^{\text {red1 }} \cdot{ }^{c} \mathrm{D}^{\prime}=\Delta E_{1 / 2}-E_{0} .{ }^{d}$ Irreversible waves.

consistent with the spectral position of the tris-dea species and suggests an excited-state electronic structure in which dea-based MLCT state(s) lie below those of the dmb ligand. Thus each successive substitution of a dmb ligand for dea smoothly shifts the absorption envelope to lower energies.

Emission Spectra. Static emission spectra for the series are shown in Figure 1b. Emission maxima of $\left[\mathrm{Ru}(\mathrm{dmb})_{3}\right]^{2+}$, $[\mathrm{Ru}-$ $\left.(\mathrm{dmb})_{2}(\mathrm{dea})\right]^{2+}$, and $\left[\mathrm{Ru}(\mathrm{dea})_{2}(\mathrm{dmb})\right]^{2+}$ occur at 630,690 , and $762 \mathrm{~nm}$, respectively. This suggests a decrease in the ${ }^{3}$ MLCT energy gap with successive dea additions and is consistent with the observed trend in the absorption spectra of these three compounds. This trend, however, is broken with $\left[\mathrm{Ru}(\mathrm{dea})_{3}\right]^{2+}$ : rather than emitting near $800 \mathrm{~nm}$, as might have been expected based on the absorption data, emission for this compound is observed at $704 \mathrm{~nm}$.

The position of the emission band for $\left[\mathrm{Ru}(\mathrm{dea})_{3}\right]^{2+}$ is surprising in that it indicates an increase in the ${ }^{3} \mathrm{MLCT} /{ }^{1} \mathrm{~A}_{1}$ energy gap relative to $\left[\mathrm{Ru}(\mathrm{dea})_{2}(\mathrm{dmb})\right]^{2+}$, despite the lower energy absorption profile of $\left[\mathrm{Ru}(\mathrm{dea})_{3}\right]^{2+}$. Since changes in the true zero-point energy difference between the emitting and ground states of a molecules do not necessarily correlate with the position of the emission maximum, we have used a spectral fitting analysis to quantify this energy gap, $E_{0}$. The details of this analysis are described elsewhere, ${ }^{31,33,34}$ but essentially, the emission envelope is modeled as a sum of Gaussians spaced by the average vibrational mode coupled to the transition. $E_{0}$ then corresponds to the highest energy Gaussian and gives the relative vertical positions of the excited- and ground-state potential surfaces, i.e., the ${ }^{3} \mathrm{MLCT} /{ }^{1} \mathrm{~A}_{1}$ gap. The results obtained for the $\mathrm{dmb} / \mathrm{dea}$ series are given in Table 2. It can be seen in the present case that the $E_{0}$ values of the complexes in this series do mirror the trends in the emission maxima: dmb-containing complexes systematically shift to lower energy with successive dea substitutions, but $\left[\mathrm{Ru}(\mathrm{dea})_{3}\right]^{2+}$ is anomalously high in energy.

The observed trend in the ${ }^{3} \mathrm{MLCT} /{ }^{1} \mathrm{~A}_{1}$ zero-point energy can be further examined by application of the energy gap law. Briefly, the energy gap law predicts an increase in vibronic coupling, and therefore, an increase in the rate of nonradiative relaxation $\left(k_{\mathrm{nr}}\right)$ as the energetic gap between two roughly nested potential energy surfaces is decreased. This theory has been successfully applied to $\left[\mathrm{Ru}(\mathrm{bpy})_{3}\right]^{2+}$ systems to explain trends in $k_{\mathrm{nr}},{ }^{4-43}$ and a linear dependence of $\ln k_{\mathrm{nr}}$ with decreasing energy gap between the lowest-lying ${ }^{3} \mathrm{MLCT}$ and the ${ }^{1} \mathrm{~A}_{1}$ ground state is generally observed. ${ }^{44}$ Time-resolved nanosecond emission data, coupled with measurements of radiative quantum yields $\left(\phi_{\mathrm{em}}\right)$, provided values of $k_{\mathrm{nr}}$ for this series of compounds.
Plotting $\ln k_{\mathrm{nr}}$ versus the $E_{0}$ values obtained from spectral fitting (Figure S1 in Supporting Information) shows that the linear correlation predicted by the energy gap law holds for these compounds. We may conclude that, while the emissive photophysics of this series do not follow the expected energetic ordering based on absorption data, no deviation from normal correlations of $E_{0}$ with $k_{\mathrm{nr}}$ occurs. This series of complexes is, in fact, well described by the energy gap law, and in order of decreasing energy gap is as follows: $\left[\mathrm{Ru}(\mathrm{dmb})_{3}\right]^{2+}>[\mathrm{Ru}-$ $(\mathrm{dmb})_{2}($ dea $\left.)\right]^{2+}>\left[\operatorname{Ru}(\mathrm{dea})_{3}\right]^{2+}>\left[\operatorname{Ru}(\mathrm{dea})_{2}(\mathrm{dmb})\right]^{2+}$.

Nanosecond Electronic and Vibrational Spectroscopies. The electronic absorption and emission data above present conflicting pictures of the electronic structure across the $\mathrm{dmb} /$ dea series. More specifically, it would appear that the simplest interpretation of the electronic absorption spectra-that of the dea ligand as the lowest energy MLCT state(s)-stands in contrast to the energy gaps derived from the analysis of the emission data. This is an exceedingly important point to resolve in terms of ultrafast measurements since successful interpretation of such data relies heavily on an understanding of the nature of both the Franck-Condon (absorption) and thermalized (emission) excited states. In order to detail the electronic structures of these compounds, we have characterized the series using nanosecond electronic and step-scan FTIR excited-state absorption spectroscopies. Both techniques allow us to probe the nature of the long-lived excited state, and subsequently aid in creating an accurate representation of the charge-transfer state(s) of the $\mathrm{dmb} / \mathrm{dea}$ series.

Excited-State Electronic Absorption. Due to the redox nature of the charge-transfer excited state in these molecules, nanosecond excited-state absorption spectra can be used in conjunction with the spectra of the electrochemically reduced and oxidized complexes to help identify the ligand (dmb vs dea) of localization and hence the relative energies of the ${ }^{3} \mathrm{MLCT}$ excited state(s)..$^{4-47}$ For example, if the charge-transfer state is localized on $\mathrm{dmb}$ in a given molecule, we can expect to see $\mathrm{dmb}^{\bullet-}$ absorptive features superimposed on ground-state bleach features in the excited-state difference spectrum. We have therefore collected both spectroelectrochemical and excited-state absorption difference spectra in order to determine the nature of the long-lived ${ }^{3}$ MLCT state(s) of these compounds.

Excited-state absorption difference spectra for all four members of the series are shown in Figure 2. The spectra of the two tris-homoleptic compounds allow determination of features characteristic of $\mathrm{dmb}^{\bullet-}$ and $\mathrm{dea}^{\bullet-}$. The excited-state difference spectrum of $\left[\mathrm{Ru}(\mathrm{dmb})_{3}\right]^{2+}$ shows two absorptions at 380 and $510 \mathrm{~nm}$, and a bleach at $450 \mathrm{~nm}$. The bleach is slightly 


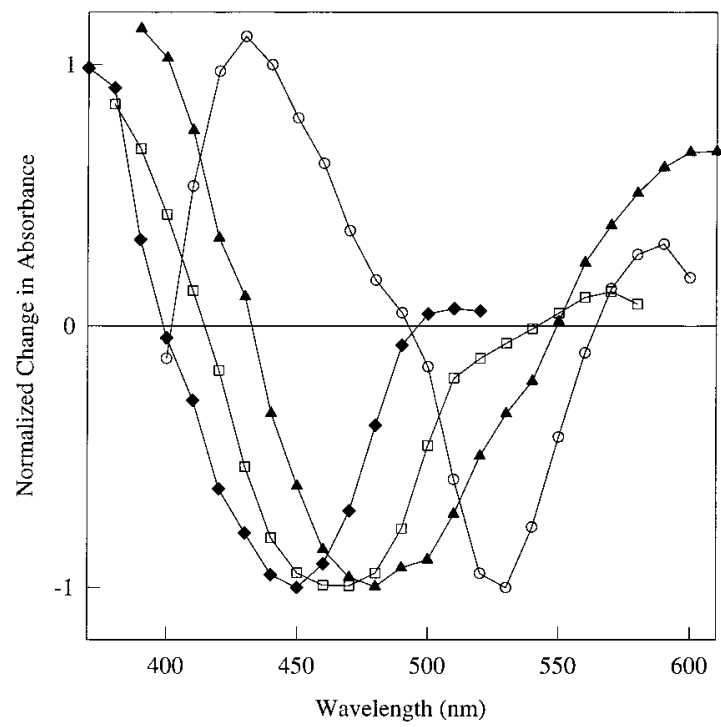

Figure 2. Nanosecond transient absorption difference spectra of $[\mathrm{Ru}-$ $\left.(\mathrm{dmb})_{3}\right]\left(\mathrm{PF}_{6}\right)_{2}(\diamond),\left[\mathrm{Ru}(\mathrm{dmb})_{2}(\mathrm{dea})\right]\left(\mathrm{PF}_{6}\right)_{2}(\square),\left[\mathrm{Ru}(\mathrm{dea})_{2}(\mathrm{dmb})\right]\left(\mathrm{PF}_{6}\right)_{2}$ $(\boldsymbol{\Delta})$, and $\left[\mathrm{Ru}(\mathrm{dea})_{3}\right]\left(\mathrm{PF}_{6}\right)_{2}(\mathrm{O})$ in deoxygenated $\mathrm{CH}_{3} \mathrm{CN}$ at $298 \mathrm{~K}$. Spectra are based on the amplitudes of single-exponential fits at each wavelength.

higher in energy than the corresponding ground-state absorption due to the nature of the difference spectrum (i.e., superposition of ground- and excited-state features). The reductive difference spectrum, corresponding to $\left[\mathrm{Ru}\left(\mathrm{dmb}^{\bullet-}\right)(\mathrm{dmb})_{2}\right]^{+}$(Figure $\mathrm{S} 2 \mathrm{~b}$, Supporting Information) exhibits absorptions at 376 and 502 $\mathrm{nm}$, in addition to a bleach at 456 . The latter feature is no doubt due to the loss of neutral dmb contributing to the overall MLCT intensity. The band at $502 \mathrm{~nm}$ is either a ligand-based absorption associated with the $\mathrm{dmb}^{\bullet-}$, or possibly a new charge-transfer transition. ${ }^{45}$ However, the band at $376 \mathrm{~nm}$ is clearly associated with the reduced dmb ligand and represents the single most distinctive feature signaling the presence of the $\mathrm{dmb}^{\bullet-}$ chromophore. We note that the relative intensities of the absorptions to the bleach are higher in this reductive spectrum than in the excited-state difference spectrum, indicating contributions from $\mathrm{Ru}^{\mathrm{III}}$-based features in the latter. When the reduction spectrum is combined with the oxidative spectrum, the electrochemically generated spectrum compares quite well with the excited-state difference spectrum (Figure S2c).

A similar analysis allows for the identification of the features unique to the dea-based excited state. The reductive spectrum of $\left[\mathrm{Ru}(\mathrm{dea})_{3}\right]^{2+}$ shows absorptions at 396 and $560 \mathrm{~nm}$, dampened by a ground-state bleach (Figure $3 b$ ). The oxidative difference spectrum exhibits a bleach at $512 \mathrm{~nm}$. It should also be noted that oxidation of this complex also results in strong absorptive features at lower energies $\left(\lambda_{\max }=756 \mathrm{~nm}\right)$, which is presumably an LMCT band. ${ }^{48}$ Again, combining the two electrochemically generated spectra results in features qualitatively similar to those observed in the excited-state difference spectrum (Figure 3c). The key feature in this case is the absorption at $\sim 400 \mathrm{~nm}$. This band, which is red-shifted from that observed for $\mathrm{dmb}^{--}$(376 $\mathrm{nm}$ ), is therefore characteristic of the $\mathrm{dea}^{\bullet-}$ chromophore.

The excited-state difference spectra of the two bis-heteroleptic complexes are somewhat more difficult to interpret in principle, since the dramatic shift in the ground-state absorption ${ }^{1}$ MLCT band across this series results in a corresponding shift in the excited-state bleach. Thus, the reductive features identified in the spectra of the tris-complexes may be less obvious to correlate with the mixed-ligand complexes due to changes in excitedstate/ground-state overlap. Nevertheless, comparison of the

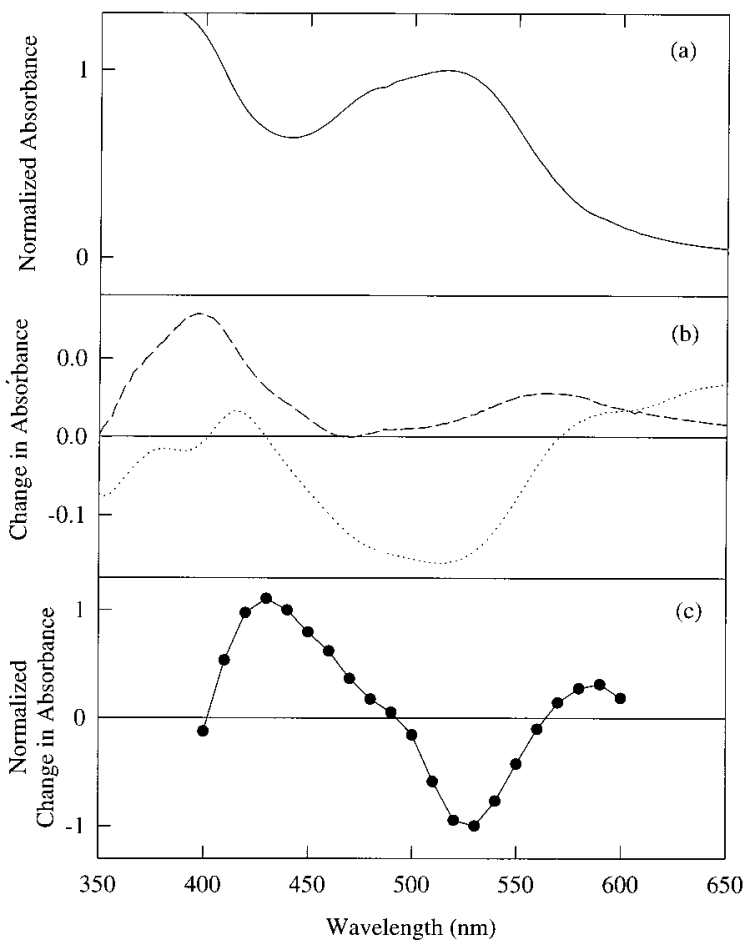

Figure 3. Comparison of ground-state and electrochemically generated difference spectra with nanosecond transient absorption difference spectra of $\left[\mathrm{Ru}(\mathrm{dea})_{3}\right]\left(\mathrm{PF}_{6}\right)_{2}$ in $\mathrm{CH}_{3} \mathrm{CN}$. (a) Ground-state absorption. (b) Reduction difference spectrum (dash) and oxidation difference spectrum (dot). (c) Excited-state difference spectrum ( $(\mathbf{)}$.

reduced ligand band energies observed in the tris-homoleptic excited-state difference spectra with those of the mixed-ligand complexes shows some obvious similarities. The absorption maxima of $\left[\mathrm{Ru}(\mathrm{dmb})_{3}\right]^{2+},\left[\mathrm{Ru}(\mathrm{dmb})_{2}(\mathrm{dea})\right]^{2+}$, and $\left[\mathrm{Ru}(\mathrm{dea})_{2^{-}}\right.$ $(\mathrm{dmb})]^{2+}$ all occur below $390 \mathrm{~nm}$, whereas the corresponding band in the spectrum of $\left[\mathrm{Ru}(\mathrm{dea})_{3}\right]^{2+}$ occurs at $430 \mathrm{~nm}$. This strongly indicates a similarity in the nature of the excited state of these first three complexes, and specifically points to a common localization of the lowest-lying ${ }^{3}$ MLCT state on dmb whenever this ligand is present. As was first revealed by the emission photophysics, $\left[\mathrm{Ru}(\mathrm{dea})_{3}\right]^{2+}$ does not follow the anticipated trend. However, unlike the emission data, the excited-state electronic absorption data points to the origin of this difference: a unique localization of the long-lived excited state on the dea ligand in only this compound. This assignment is consistent with other features of the excited-state spectra. For example, the broadening of the bleach feature in the mixedligand complexes, where the ground-state bleach is shifting to lower energy relative to $\left[\mathrm{Ru}(\mathrm{dmb})_{3}\right]^{2+}$, is due to decreased overlap with the high-energy $\mathrm{dmb}^{--}$band. The bleach is again narrowed in the tris(dea) complex because of the new, lower energy dea ${ }^{--}$absorption band. Again, the common lowest energy feature in all dea-containing complexes (below $550 \mathrm{~nm}$ ) is most likely increased LMCT absorption intensity, as observed previously in similar complexes. ${ }^{48}$

Step-Scan FTIR. The excited-state absorption and electronic spectroelectrochemical data provide compelling evidence for ${ }^{3}$ MLCT localization on the dmb ligand in all three dmbcontaining compounds. Further support for this can be obtained from analogous vibrational spectroscopic studies. ${ }^{49}$ The most common excited-state vibrational technique applied to transition metal polypyridyls has been time-resolved resonance Raman spectroscopy. ${ }^{11,20,21,23}$ This technique has the advantage of selectivity in that resonant scattering off the ligand radical anion 


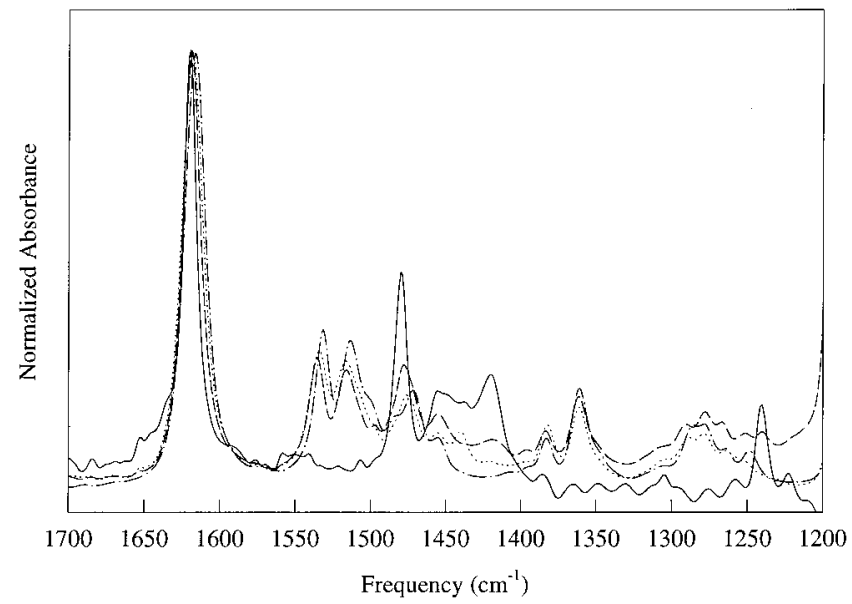

Figure 4. Ground-state FTIR spectra of $\left[\mathrm{Ru}(\mathrm{dmb})_{3}\right]\left(\mathrm{PF}_{6}\right)_{2}$ (solid), $[\mathrm{Ru}$ $\left.(\mathrm{dmb})_{2}(\mathrm{dea})\right]\left(\mathrm{PF}_{6}\right)_{2}$ (dash), $\left[\mathrm{Ru}(\mathrm{dea})_{2}(\mathrm{dmb})\right]\left(\mathrm{PF}_{6}\right)_{2}$ (dot), and $\left[\mathrm{Ru}(\mathrm{dea})_{3}\right]-$ $\left(\mathrm{PF}_{6}\right)_{2}$ (dash-dot) in deoxygenated $\mathrm{CD}_{3} \mathrm{CN}$ at $298 \mathrm{~K}$.

absorption in the excited-state ensures selective probing of the ligand on which the ${ }^{3}$ MLCT state is localized. However, in so doing, resonance Raman provides an incomplete picture of the excited-state structure. Recently, time-resolved step-scan FTIR spectroscopy has also been applied to transition metal bipyridyl complexes, in both the carbonyl ${ }^{50-53}$ and mid-infrared ${ }^{24,54}$ spectral regions. We have collected nanosecond time-resolved step-scan FTIR and spectroelectrochemical data for all four members of the $\mathrm{dmb} / \mathrm{dea}$ series, the first application of stepscan FTIR to the mid-infrared region of asymmetric ruthenium bipyridyl complexes. The nonselective nature of the IR measurement allows for a more complete description of the ${ }^{3} \mathrm{MLCT}$ state. The electron localization on a single bpy ligand in the long-lived excited state of ruthenium bipyridyl complexes has specific implications for the complexity of their excited-state infrared spectra, particularly in the mixed-ligand systems. However, as we will show, simulation and interpretation of excited-state spectra can be achieved through use of spectroelectrochemistry.

Figure 4 shows the ground-state FTIR spectra for the series. It has been established that the mid-IR region of the spectrum of $\left[\mathrm{Ru}(\mathrm{bpy})_{3}\right]^{2+}$ is composed primarily of bpy ring-breathing modes that may be appropriately modeled as (three) single coordinated bipyridines in $C_{2 v}$ symmetry. ${ }^{55,56}$ Assuming this is a suitable approximation for this series of substituted-bpy complexes, the ground-state spectra follow a logical progression as $\mathrm{dmb}$ is substituted for dea across the series. For example, the strong $1620 \mathrm{~cm}^{-1}$ band in the $\left[\mathrm{Ru}(\mathrm{dmb})_{3}\right]^{2+}$ spectrum is seen to shift and broaden with each successive dea addition toward the corresponding $1617 \mathrm{~cm}^{-1}$ band in $\left[\mathrm{Ru}(\mathrm{dea})_{3}\right]^{2+}$. Similarly, the intensity decrease and shift to lower frequency of the $1480 \mathrm{~cm}^{-1}$ band in $\left[\mathrm{Ru}(\mathrm{dmb})_{3}\right]^{2+}$ to the $1472 \mathrm{~cm}^{-1}$ band in $\left[\mathrm{Ru}(\mathrm{dea})_{3}\right]^{2+}$ tracks ligand substitution. $\left[\mathrm{Ru}(\mathrm{dea})_{3}\right]^{2+}$ features at 1532 and $1513 \mathrm{~cm}^{-1}$ first appear in $\left[\operatorname{Ru}(\mathrm{dmb})_{2}(\mathrm{dea})\right]^{2+}$ and then increase in intensity in the $\left[\mathrm{Ru}(\mathrm{dea})_{2}(\mathrm{dmb})\right]^{2+}$ spectrum. Bands near 1383 and $1361 \mathrm{~cm}^{-1}$ also appear with addition of dea to the complex, as do features in the $1300-1250 \mathrm{~cm}^{-1}$ region.

The complexity that arises due to localization of the excitedstate electron on one ligand in the infrared spectrum (as opposed to resonance Raman) is immediately obvious from an examination of the nanosecond excited-state difference spectra (Figure 5). Even the excited-state spectrum of a "simple" homoleptic complex, such as $\left[\mathrm{Ru}(\mathrm{dmb})_{3}\right]^{2+}$, contains two sets of bandsone for each of two sets of ring-breathing modes-due to the
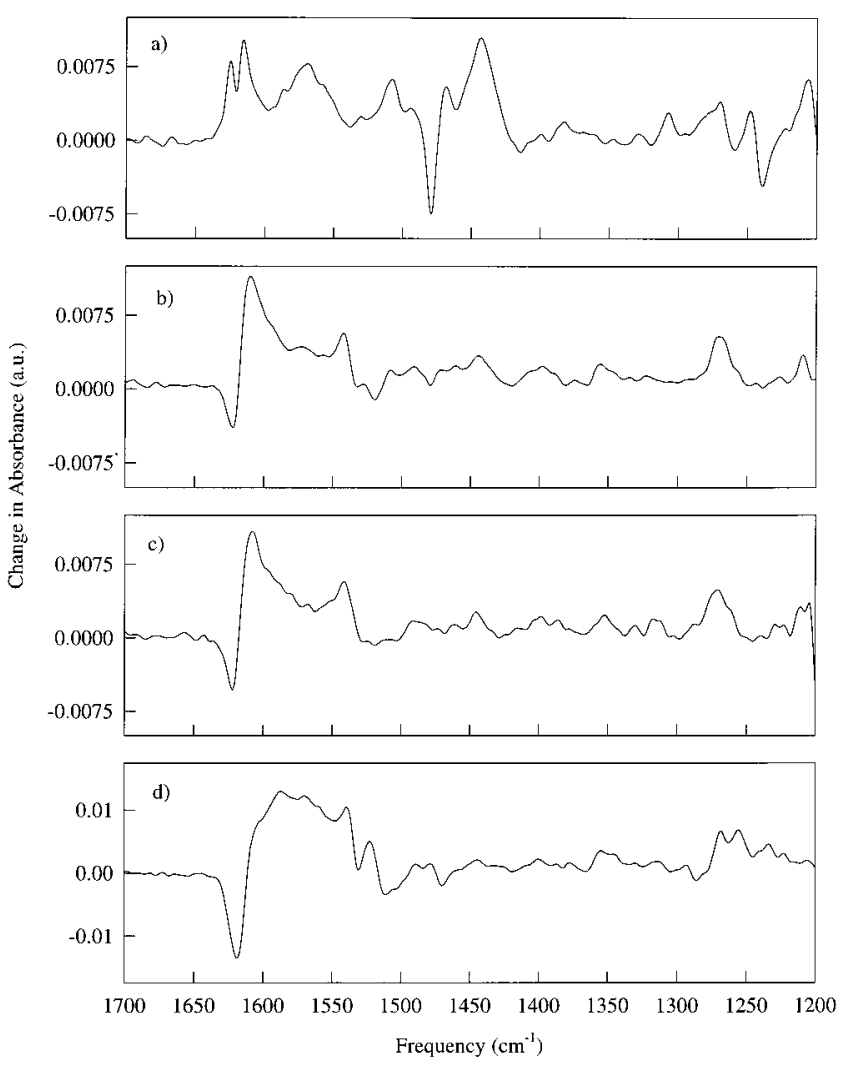

Figure 5. Nanosecond step-scan FTIR absorption difference spectra of (a) $\left[\mathrm{Ru}(\mathrm{dmb})_{3}\right]\left(\mathrm{PF}_{6}\right)_{2}$, (b) $\left[\mathrm{Ru}(\mathrm{dmb})_{2}(\mathrm{dea})\right]\left(\mathrm{PF}_{6}\right)_{2}$, (c) $\left[\mathrm{Ru}(\mathrm{dea})_{2}(\mathrm{dmb})\right]-$ $\left(\mathrm{PF}_{6}\right)_{2}$, and $(\mathrm{d})\left[\mathrm{Ru}(\mathrm{dea})_{3}\right]\left(\mathrm{PF}_{6}\right)_{2}$ in deoxygenated $\mathrm{CD}_{3} \mathrm{CN}$ at $298 \mathrm{~K}$.

presence of both neutral and reduced dmb ligands. This being the case, three sets of features will occur in the excited-state difference spectrum: (1) ground-state $\mathrm{Ru}^{\mathrm{II}}$-dmb bleaches, (2) $\mathrm{Ru}^{\mathrm{III}}$-dmb absorptions, and (3) $\mathrm{Ru}^{\mathrm{III}}-\mathrm{dmb}^{\bullet-}$ absorptions. This was recently reported for the nanosecond difference spectrum of $\left[\mathrm{Ru}(\mathrm{bpy})_{3}\right]^{2+} .{ }^{24}$ In that study, the spectra of electrochemically generated $\left[\mathrm{Ru}^{\mathrm{II}}\left(\mathrm{bpy}^{\bullet-}\right)(\mathrm{bpy})_{2}\right]^{+}$and $\left[\mathrm{Ru}^{\mathrm{III}}(\mathrm{bpy})_{3}\right]^{3+}$ species were correlated with the two sets of excited-state absorptive features of $\mathrm{Ru}^{\mathrm{III}}-\mathrm{bpy}{ }^{\bullet-}$ and $\mathrm{Ru}^{\mathrm{III}}$-bpy, respectively. However, even in homoleptic complexes, such assignments can be complicated by the overlap of absorptions and bleaches. For example, the two absorption features in the excited-state difference spectrum of $\left[\mathrm{Ru}(\mathrm{dmb})_{3}\right]^{2+}$ at 1625 and $1615 \mathrm{~cm}^{-1}$ are most likely the result of an overlapping ground-state bleach (at $1620 \mathrm{~cm}^{-1}$ ) with an excited-state absorption of greater intensity (Figure 5a). In the case of mixed-ligand complexes, this problem is compounded as the number of different sets of breathing mode vibrations increases. A summary of the expected sets of vibrational band types and degeneracies for the four compounds in this series is given in Table S1 (Supporting Information).

Despite these complications, comparison of ground- and excited-state spectra reveals several immediate correlations between ground-state absorptions and excited-state bleaches. $\left[\mathrm{Ru}(\mathrm{dmb})_{3}\right]^{2+}$ excited-state bleaches at 1621 and $1479 \mathrm{~cm}^{-1}$, for example, correspond directly to absorptive features in the ground-state spectrum. The asymmetric bleach at $1239 \mathrm{~cm}^{-1}$ and absorption at $1248 \mathrm{~cm}^{-1}$ are likely the result of overlap of a $1240 \mathrm{~cm}^{-1}$ ground-state bleach with an excited-state absorption. Similarly, the excited-state $\left[\mathrm{Ru}(\mathrm{dea})_{3}\right]^{2+}$ asymmetric bleach at $1619 \mathrm{~cm}^{-1}$ results from the overlap of a $1617 \mathrm{~cm}^{-1}$ bleach and an excited-state absorption. Overlapping bleach and absorptive features are also observed for the mixed-ligand complexes in this region (approximately $1625-1500 \mathrm{~cm}^{-1}$ ). The excited- 


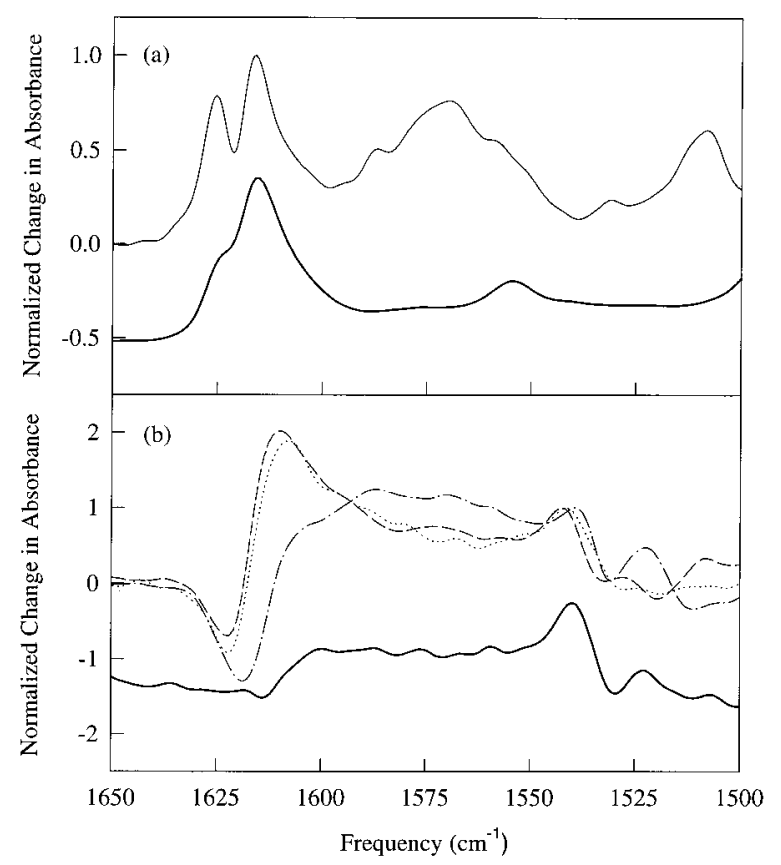

Figure 6. Comparison of nanosecond step-scan FTIR excited-state difference spectra with electrochemically generated oxidation difference spectra of the tris complexes in deoxygenated $\mathrm{CD}_{3} \mathrm{CN}$ at $298 \mathrm{~K}$. (a) $\left[\mathrm{Ru}(\mathrm{dmb})_{3}\right]^{2+}$ excited-state (solid) and oxidative (dark solid) difference spectra, normalized to the maxima near $1615 \mathrm{~cm}^{-1}$. The spectra have been vertically offset for easier viewing. (b) The oxidative difference spectrum of $\left[\mathrm{Ru}(\mathrm{dea})_{3}\right]\left(\mathrm{PF}_{6}\right)_{2}$ (dark solid) compared with the excitedstate difference spectra of $\left[\mathrm{Ru}(\mathrm{dmb})_{2}(\mathrm{dea})\right]\left(\mathrm{PF}_{6}\right)_{2}$ (dash), $\left[\mathrm{Ru}(\mathrm{dea})_{2}-\right.$ $(\mathrm{dmb})]\left(\mathrm{PF}_{6}\right)_{2}(\mathrm{dot})$, and $\left[\mathrm{Ru}(\mathrm{dea})_{3}\right]\left(\mathrm{PF}_{6}\right)_{2}$ (dash-dot). All are normalized to same absorbance intensity of the $1540 \mathrm{~cm}^{-1}$ region maximum.

state absorptions appear to be shifting across the series to lower frequency relative to the corresponding ground-state bleach of the complex. The "intermediate" appearance of the mixed complexes, in which the bleach and absorption bands appear to have similar positions and intensities, are likely the result of common lower frequency absorptions (similar to $\left[\mathrm{Ru}(\mathrm{dea})_{3}\right]^{2+}$ ) and common higher frequency bleaches $\left(\left[\mathrm{Ru}(\mathrm{dmb})_{3}\right]^{2+}\right)$. This interpretation is consistent with $\mathrm{dmb}$ localization in all three dmb-containing compounds, i.e., the loss of $\mathrm{Ru}^{\mathrm{II}}$-dmb groundstate features and the introduction of $\mathrm{Ru}^{\mathrm{III}}$-dea features in the mixed-ligand complexes. We note that averaging the excitedstate spectra of $\left[\mathrm{Ru}(\mathrm{dmb})_{3}\right]^{2+}$ and $\left[\mathrm{Ru}(\mathrm{dea})_{3}\right]^{2+}$ yields a simulated spectrum that qualitatively resembles the mixed-ligand excited-state spectra. However, due to the constantly varying composition of the excited state, this type of analysis is necessarily limited.

Further comparison and deconvolution of spectral features requires the use of spectroelectrochemistry. We have obtained difference spectra of the oxidative products of the tris-homoleptic complexes, $\left[\mathrm{Ru}^{\mathrm{III}}(\mathrm{dmb})_{3}\right]^{3+}$ and $\left[\mathrm{Ru}^{\mathrm{III}}(\mathrm{dea})_{3}\right]^{3+}$, and compared these with the excited-state difference spectra of all four complexes. If the ${ }^{3}$ MLCT excited state is indeed localized on the dmb ligand in the first three complexes of the series, then the only bands common to the excited-state spectra of [Ru$\left.(\mathrm{dmb})_{2}(\mathrm{dea})\right]^{2+},\left[\operatorname{Ru}(\mathrm{dea})_{2}(\mathrm{dmb})\right]^{2+}$, and $\left[\mathrm{Ru}(\mathrm{dea})_{3}\right]^{2+}$ should be $\mathrm{Ru}^{\mathrm{III}}$-dea-based absorptions. Absorption bands at 1539 (Figure 6) and $1355 \mathrm{~cm}^{-1}$ are observed in both excited-state and oxidative $\left[\mathrm{Ru}(\mathrm{dea})_{3}\right]^{2+}$ spectra, and these are the only bands common to all dea-containing complexes and moreover are absent in $\left[\mathrm{Ru}(\mathrm{dmb})_{3}\right]^{2+}$. The $\left[\mathrm{Ru}(\mathrm{dea})_{3}\right]^{2+} 1400 \mathrm{~cm}^{-1}$ band may also fall into this category, but the oxidative $\left[\mathrm{Ru}(\mathrm{dea})_{3}\right]^{2+}$ spectrum was less reproducible in this region due to complica- tions with the solvent. The broadened, relatively featureless region $\left(1600-1550 \mathrm{~cm}^{-1}\right)$ in the excited-state spectra of all deacontaining complexes is also observed in the $\left[\mathrm{Ru}(\mathrm{dea})_{3}\right]^{2+}$ oxidation difference spectrum and further suggests the presence of $\mathrm{Ru}^{\mathrm{III}}$-dea in all three dea-containing complexes.

The area exhibiting the most intense absorption features in the excited-state spectra $\left(1650-1550 \mathrm{~cm}^{-1}\right)$ is unfortunately the most difficult to interpret due to an overlap of strong positive and negative contributions. The most prominent feature in the oxidative spectrum of $\left[\mathrm{Ru}(\mathrm{dmb})_{3}\right]^{2+}$ is a large absorption at 1616 $\mathrm{cm}^{-1}$. As mentioned, less intense and broadened features appear at lower frequencies in the oxidative spectrum of $\left[\mathrm{Ru}(\mathrm{dea})_{3}\right]^{2+}$. This, in convolution with the higher frequency bleach expected for the $\mathrm{Ru}^{\mathrm{III}}-\mathrm{dmb}^{\bullet-}$ chromophore relative to $\mathrm{Ru}^{\mathrm{III}}-\mathrm{dea}^{--}$(1620 vs $1617 \mathrm{~cm}^{-1}$ ), produces the general shape of the spectra of the mixed-ligand complexes in this region. An increase in lower frequency, but lower intensity, absorptions due to a second dea ligand could account for the slight increase in bleach and decrease in absorption (at approximately 1622 and $1607 \mathrm{~cm}^{-1}$ ) between $\left[\mathrm{Ru}(\mathrm{dmb})_{2}(\mathrm{dea})\right]^{2+}$ and $\left[\mathrm{Ru}(\mathrm{dea})_{2}(\mathrm{dmb})\right]^{2+}$. The strong bleach at $1479 \mathrm{~cm}^{-1}$ is also observed in both excited-state and oxidative $\left[\mathrm{Ru}(\mathrm{dmb})_{3}\right]^{2+}$ spectra. A corresponding small bleach is observed in $\left[\mathrm{Ru}(\mathrm{dmb})_{2}(\mathrm{dea})\right]^{2+}$ that does not appear in either the bis(dea) or tris(dea) complexes (Figure 5). It should be reiterated that these IR absorption difference spectra are superpositions of many absorptions and bleaches, and as both $\left[\mathrm{Ru}(\mathrm{dea})_{2}(\mathrm{dmb})\right]^{2+}$ and $\left[\mathrm{Ru}(\mathrm{dea})_{3}\right]^{2+}$ have slightly positive absorptions at $1479 \mathrm{~cm}^{-1}$, it is perhaps not surprising that only a very weak bleach appears in the spectrum of $\left[\mathrm{Ru}(\mathrm{dmb})_{2^{-}}\right.$ $($ dea $)]^{2+}$. Obviously, the reductive spectra of the tris complexes, as well as the oxidative and reductive spectra of mixed-ligand species, would be required to assign every band in the excitedstate spectra. While we will not make such an exhaustive assignment here, all of the above observations are consistent with our assignment of dmb localization of the ${ }^{3}$ MLCT excited state in all three molecules in which this ligand is present.

In concluding this section, we wish to note that, while the interpretation of these infrared spectra is obviously much less straightforward than the more common resonance Raman data with regard to ${ }^{3}$ MLCT localization, there is far more structural information available from the infrared measurement. The methodology described herein is generally applicable and represents an additional means for elucidating the electronic structure of heteroleptic complexes.

Electrochemistry. Correlations between spectroscopic MLCT energies and redox potentials in ruthenium polypyridyl complexes are well established. ${ }^{1,57}$ The photoinduced charge-transfer process can be described in terms of a simultaneous metal oxidation and ligand reduction (eq 1). However, unlike photophysical data, electrochemical measurements allow the energy of each of these processes to be determined separately. We have therefore collected electrochemical data (Table 2) on the dmb/ dea series in order to gain further insight into the origin of the excited-state localization patterns established in the preceding discussion.

Both oxidative and reductive electrochemical data are given in Table 2. The most striking trend is the dramatic shift in the oxidative $\mathrm{Ru}^{\mathrm{II} / \mathrm{III}}$ couple upon addition of the dea ligand. Substitution of a single dmb for dea to give $\left[\mathrm{Ru}(\mathrm{dmb})_{2}(\mathrm{dea})\right]^{2+}$, for example, results in a lowering of the metal oxidation potential $\left(E_{1 / 2}{ }^{\mathrm{ox}}\right)$ by more than $300 \mathrm{mV}$ compared to [Ru$\left.(\mathrm{dmb})_{3}\right]^{2+}$. This trend continues with successive dea substitutions, lowering the oxidation potential of the metal center by over $200 \mathrm{mV}$ with each additional dea ligand. This indicates 
that the presence of dea in the coordination sphere of $\mathrm{Ru}^{\mathrm{II}}$ increases electron density at the metal center and implies a strong effect of the dea ligand on the filled $t_{2}$ orbitals of $\mathrm{Ru}^{\mathrm{II}}$. We shall return to this point later in the discussion.

The first reduction potentials $\left(E_{1 / 2}{ }^{\text {red }}\right)$ of the series show a simultaneous trend, becoming increasingly negative across the series with successive dea incorporation, indicating increasing difficulty in ligand reduction. Notice, however, that this trend is not continuous: $E_{1 / 2}$ red1 changes by only $0.08 \mathrm{~V}$ upon going from $\left[\mathrm{Ru}(\mathrm{dmb})_{3}\right]^{2+}$ to $\left[\mathrm{Ru}(\mathrm{dmb})_{2}(\mathrm{dea})\right]^{2+}$ and by $0.09 \mathrm{~V}$ for the next member of the series, $\left[\mathrm{Ru}(\mathrm{dea})_{2}(\mathrm{dmb})\right]^{2+}$. The reduction potential then jumps by $0.24 \mathrm{~V}$ between the last dmb containing complex and $\left[\mathrm{Ru}(\mathrm{dea})_{3}\right]^{2+}$. This discontinuity in $E_{1 / 2}{ }^{\text {redl }}$ between $\left[\mathrm{Ru}(\mathrm{dea})_{2}(\mathrm{dmb})\right]^{2+}$ and $\left[\mathrm{Ru}(\mathrm{dea})_{3}\right]^{2+}$ is similar to the change in $E_{1 / 2}{ }^{\text {red} 2}$ between $\left[\mathrm{Ru}(\mathrm{dmb})_{2}(\mathrm{dea})\right]^{2+}$ and $\left[\mathrm{Ru}(\mathrm{dea})_{2}(\mathrm{dmb})\right]^{2+}$ and that observed in $E_{1 / 2}{ }^{\text {red3 }}$ between $\left[\mathrm{Ru}(\mathrm{dmb})_{3}\right]^{2+}$ and $\left[\mathrm{Ru}(\mathrm{dmb})_{2-}\right.$ $(d e a)]^{2+}$. From these data we can immediately infer that dea is more difficult to reduce than dmb, indicating a higher energy $\pi^{*}$ LUMO for the dea ligand. This result alone would suggest that charge-transfer bands involving dea should occur at a higher energy than for dmb. However, since the observed trend in reduction potential is smaller in magnitude than the shift in $E_{1 / 2}{ }^{\text {ox }}$ across the series, it is the shift in the ruthenium potentials $\left(E_{1 / 2}{ }^{\mathrm{ox}}\right)$ that dominates the electronic structure changes that occur across the series. This is reflected in the absorption spectra of the compounds.

The analysis of the energy gaps from the electrochemical data, however, does present a problem: the predicted MLCT/ ${ }^{1} \mathrm{~A}_{1}$ zero-point energy differences for $\left[\mathrm{Ru}(\mathrm{dea})_{2}(\mathrm{dmb})\right]^{2+}$ and $[\mathrm{Ru}-$ $\left.(\mathrm{dea})_{3}\right]^{2+}$ are identical within experimental error (Table 2). This is clearly at variance with the emission energies. To understand this, we examine the series in the context of the established linear relationship between emission energy and redox potentials. ${ }^{58}$ Lever and co-workers ${ }^{59}$ have defined a $D$ parameter that relates emission and electrochemical quantities as follows

$$
\Delta E_{1 / 2}-E_{00}=D
$$

where $E_{00}$ is the highest energy vibronic component in the 77 $\mathrm{K}$ emission spectrum and $\Delta E_{1 / 2}$ is the potential difference between the oxidation and first reduction potentials $\left(\Delta E_{1 / 2}=\right.$ $E_{1 / 2}{ }^{\text {ox }}-E_{1 / 2}{ }^{\text {red }}$ ). The parameter $\mathrm{D}$ is therefore a thermodynamic quantity that accounts for free energy differences due to the nature of the redox orbital: the reduction of a ligand in $\mathrm{a} \mathrm{Ru}^{\mathrm{III}}$ environment (spectroscopic) versus the same ligand reduction in $\mathrm{a} \mathrm{Ru}^{\mathrm{II}}$ environment (electrochemical), and the energy differences associated with the corresponding metal oxidation in the two possible ligand environments (i.e., neutral and reduced). The $D$ parameter includes both Coulombic and solvational contributions to these energy differences. For a set of more than 70 ruthenium diimine complexes, the average $D$ value was found to be $0.48 \pm 0.09 \mathrm{~V}\left(3900 \pm 700 \mathrm{~cm}^{-1}\right)$.

Examination of the $D$ parameter in this series allows us to address the apparent flaw in the connection between emission and electrochemical data, namely, the relative ${ }^{3} \mathrm{MLCT}$ gaps of $\left[\mathrm{Ru}(\mathrm{dea})_{2}(\mathrm{dmb})\right]^{2+}$ and $\left[\mathrm{Ru}(\mathrm{dea})_{3}\right]^{2+}$. As indicated above, the trend in $E_{1 / 2}{ }^{\text {ox }}$ successfully accounts for the progression of the absorption spectra, and trends in reduction potentials point to $\mathrm{dmb}$ as having the lowest energy LUMO. However, emission data indicate that the ${ }^{3} \mathrm{MLCT} \rightarrow{ }^{1} \mathrm{~A}_{1}$ transition energy of [Ru$\left.(\mathrm{dea})_{2}(\mathrm{dmb})\right]^{2+}$ is significantly lower than that of $\left[\mathrm{Ru}(\mathrm{dea})_{3}\right]^{2+}$, in contrast to the gaps predicted by the electrochemical data (Table 2). While it is true that the $\Delta E_{1 / 2}$ values do not quantitatively correspond to the relative emission energies of these complexes, it is important to remember that these

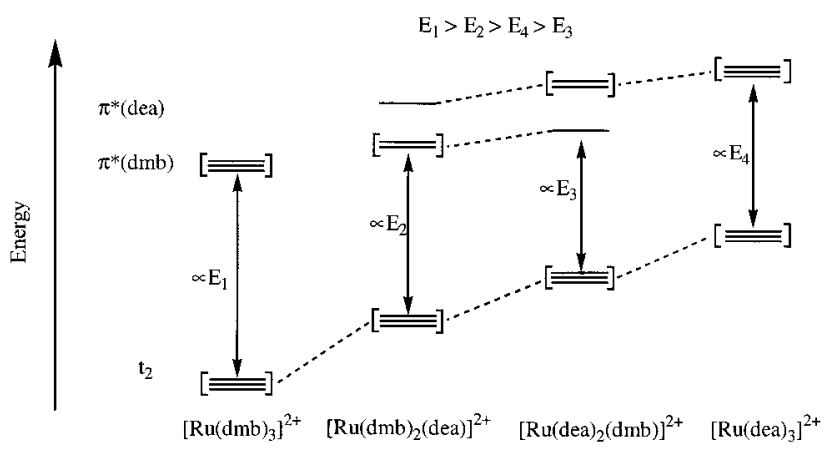

Figure 7. Simplified energy level diagram for the $\mathrm{dmb} / \mathrm{dea}$ series, showing trends in orbital and term state energies. The latter are described by $E_{i}(i=1-4)$ and refer to the ${ }^{3} \mathrm{MLCT} /{ }^{1} \mathrm{~A}_{1}$ energy gap for each molecule. See text for further details.

electrochemical values neglect differences in charge repulsion and solvation energies, factors that are included in the $D$ parameter. We have used the energy gap values obtained from spectral fitting $\left(E_{0}\right)$ as a thermodynamic quantity similar to the $E_{00}$ parameter used by Lever ${ }^{59}$ to give an estimation of the difference in MLCT energy gap predicted electrochemically and that observed spectroscopically. Table 2 lists our calculated $D^{\prime}$ values, where $D^{\prime}=\Delta E_{1 / 2}-E_{0}$. The marked dissimilarity in the value of $D^{\prime}$ between all dmb-containing complexes and [Ru$\left.(\mathrm{dea})_{3}\right]^{2+}$ reinforces the notion of a commonality between these first three complexes. A tendency for $D$ to increase with increasing $\mathrm{Ru}^{\mathrm{II} / \mathrm{III}}$ potential $\left(E_{1 / 2}{ }^{\mathrm{red}}\right)$ was noted by Lever, and we see that $D^{\prime}$ is indeed largest for $\left[\mathrm{Ru}(\mathrm{dmb})_{3}\right]^{2+}$. All of our values for $D^{\prime}$ also fall within the reported range of the 70 diimine complexes mentioned above. It is difficult to know with certainty the origin of the anomalously small value of $D^{\prime}$ for $\left[\mathrm{Ru}(\mathrm{dea})_{3}\right]^{2+}$. It can be expected that solvent reorganization energies will be larger in complexes with more solvent interaction, increasing the apparent $E_{00}$ value and decreasing the value of $D$. These and other subtle differences may be contributing to the incongruous $D^{\prime}$ value seen for $\left[\mathrm{Ru}(\mathrm{dea})_{3}\right]^{2+}$. However, the dissimilarity in these neglected factors evidenced by $D^{\prime}$ is yet another indication that the lowest energy excited state is different in this last complex, where it becomes localized on the dea ligand for the first time in this series. Since the lowest $\pi^{*}$ level is the same for the first three complexes and differs for [Ru$\left.(\text { dea })_{3}\right]^{2+}$, a significant change in the value of $D^{\prime}$ might be expected.

Despite the deviations from the quantitative correlations seen in other substituted bipyridine complexes, the inconsistencies between electrochemical and photophysical data can be readily understood. Thus, when the electrochemical and spectroscopic data are combined, a cohesive picture for the electronic structure of the series is obtained (Figure 7).

Understanding the Origin of the Trends. The magnitude of the changes in emission energy across this series is large compared to what is generally observed in other substitutedbipyridine systems. ${ }^{1,11}$ However, a comparable change in absorption and emission energies has been documented in a series containing $\mathrm{CF}_{3}$-substituted bipyridines. ${ }^{13}$ In this case, the dramatic shift was attributed to the introduction of a low-lying $\pi^{*}$ level residing on the $\mathrm{CF}_{3}$ ligand, thus leading to localization of the ${ }^{3} \mathrm{MLCT}$ state on the $\mathrm{CF}_{3}$-containing ligand in mixedligand complexes. As shown by the preceding discussions, such is not the case in our system, despite the indication of the absorption spectral trend.

Excited-state absorption spectra indicate that the decreasing MLCT energy gap across the series is not due to the introduction 
of new, lower lying $\pi^{*}$ levels on dea, but rather that chargetransfer to dmb represents the lowest energy excited state of the system. Electrochemical data verify this energetic ordering and indicate that destabilization of the ruthenium $t_{2}$ orbitals by the dea ligand is responsible for the shift of the MLCT band to lower energy. Similar energetic schemes have been put forth for other systems. Mabrouk and Wrighton, ${ }^{11}$ for example, have attributed such trends in absorption and emission energies in a bpy/dmb series to the electron-donating ability of the dmb ligand (relative to bpy) and its effect on the Ru $\mathrm{t}_{2}$ levels. The magnitude of the largest emission energy difference $\left(\sim 450 \mathrm{~cm}^{-1}\right)$ in this bpy/dmb series is, however, much less dramatic than that observed in our dea containing series $\left(\sim 2750 \mathrm{~cm}^{-1}\right)$. A decrease in the ${ }^{3}$ MLCT state energy has also been observed with $4,4^{\prime}$ dicarboxy-2,2'-bipyridine ${ }^{14}$ and 4,4'-di-( $p$-carboxyphenyl)-2,2' bipyridine $^{15}$ ruthenium complexes, an effect attributed to increased charge density at the metal center. Oxidation of the metal is also seen to be facilitated by the increased charge density on ruthenium in complexes containing the diamino-, bis(dimethylamino)-, and bis(diethylamino)-2,2'-bipyridine ligands. ${ }^{48}$ In these systems, ligand-to-metal transfer (LMCT) transitions were investigated and led to development of an energetic scheme that is consistent with Figure 7. In our series, it is the strong electron-donating ability of the diethylamino substituent on the dea ligand that results in the dramatic effect on MLCT energies. A possible resonance structure for the complex is one in which the diethylamino nitrogen forms a double bond with the bipyridine ring. This results in a substantial increase in electron donation to the metal center, thereby facilitating the oxidization from $\mathrm{Ru}^{\mathrm{II}}$ to $\mathrm{Ru}^{\mathrm{III}}$. The trend can also be understood from the perspective of molecular orbital theory, in which the lower energy $\mathrm{dmb} \pi^{*}$ levels will overlap more effectively with the $t_{2}$ levels, resulting in a larger splitting and therefore a larger MLCT gap.

Static Absorption and Emission Photophysics Revisited. Having determined the lowest energy ligand and discussed the nature of the energetic trends, it is worth revisiting static absorption and emission photophysics, particularly that of the bis-heteroleptic complexes. With respect to emission data, our initial assumption that dea was the lower energy of the two ligands, based on the relative absorption energies of the trishomoleptic complexes, did not allow us to account for the anomalous behavior of $\left[\mathrm{Ru}(\mathrm{dea})_{3}\right]^{2+}$. Given a lowest energy dmb-based $\pi^{*}$ level, the relative emission energy of the tris(dea) complex can be rationalized. The transition from $[\mathrm{Ru}-$ $\left.(\text { dea })_{2}(\mathrm{dmb})\right]^{2+}$ to $\left[\mathrm{Ru}(\mathrm{dea})_{3}\right]^{2+}$, then, removes the lowest $\pi^{*}$ level present in the first three dmb-containing complexes of the series, and the trend observed in the first three complexes is broken. This is reflected in the Stokes shift variation across the series: $\left[\mathrm{Ru}(\mathrm{dmb})_{3}\right]^{2+},\left[\mathrm{Ru}(\mathrm{dmb})_{2}(\mathrm{dea})\right]^{2+}$, and $\left[\mathrm{Ru}(\mathrm{dea})_{2^{-}}\right.$ $(\mathrm{dmb})]^{2+}$ exhibit differences of 5961, 6693, and $7369 \mathrm{~cm}^{-1}$, respectively. This is due to the successive weighting of the absorption band toward the higher energy $t_{2} \rightarrow \pi^{*}$ (dea) transition with each additional dea and a concomitant decrease in the MLCT energy gap relevant for emission (i.e., $\pi^{*}(\mathrm{dmb}) \rightarrow \mathrm{t}_{2}$ ). Accordingly, the shift for $\left[\mathrm{Ru}(\mathrm{dea})_{3}\right]^{2+}$ is $5100 \mathrm{~cm}^{-1}$, reflecting the fact that, as in $\left[\mathrm{Ru}(\mathrm{dmb})_{3}\right]^{2+}$, both absorption and emission involve the same single ligand type.

It was noted earlier that the broadening of the absorption bands of these two mixed complexes could be attributed to the existence of MLCT states associated with different ligands, in this sense, nondegenerate energy levels. The weighting of these bands toward higher energy in the case of the doubly degenerate $\mathrm{dmb}$ complex and lower energy in the bis(dea) complex was most intuitively explained with the dmb ligand as the higher energy ligand, contrary to what we have just asserted. However, it is also possible to rationalize this weighting by noting that the presence of two dea ligands has nearly twice the effect on the energy of the $\mathrm{Ru}^{\mathrm{II} / \mathrm{III}}$ couple as one dea ligand. This being the case, both dmb and dea MLCT gaps will be smaller in the bis(dea) complex relative to the bis(dmb) complex, and the whole absorption envelope of $\left[\mathrm{Ru}(\mathrm{dea})_{2}(\mathrm{dmb})\right]^{2+}$ will be shifted to lower energies. This is despite the fact that the doubly degenerate dea MLCT level is, as always, at a relatively higher energy than dmb in the same complex, which is always the low energy shoulder of the absorption band. In other words, dea substitution for dmb introduces a new, higher energy $t_{2} \rightarrow$ $\pi^{*}$ (dea) transition, but also lowers the energy of the $t_{2} \rightarrow$ $\pi^{*}(\mathrm{dmb})$ transition, and the energy of both types of absorptive transitions are therefore lower in $\left[\mathrm{Ru}(\mathrm{dea})_{2}(\mathrm{dmb})\right]^{2+}$.

\section{Concluding Comments}

We have presented the results of a detailed spectroscopic study that reveals the excited-state electronic structure in a series of low-symmetry $\mathrm{Ru}^{\mathrm{II}}$ polypyridyl complexes. Specifically, bisheteroleptic compounds, in which two different bipyridyl ligands are bound to the metal center, were examined as a prelude to studies of their excited-state dynamics by excitation wavelengthdependent femtosecond absorption spectroscopy. Whereas groundstate electronic absorption spectra of the $\left[\mathrm{Ru}(\mathrm{dmb})_{x}(\mathrm{dea})_{3-x}\right]^{2+}$ series imply one picture of the relative energetics within the MLCT manifold, examination of static and time-resolved emission, electronic absorption, and infrared spectra across the series revealed that this picture was incorrect. The electronic structure inferred from static absorption is, in fact, the opposite of what is established through the more extensive characterization.

In concluding, we wish to stress what we feel is the importance of this result. The ultrafast spectroscopy of transition metal complexes is a relatively undeveloped area of photophysics. While there are a host of interesting problems to be examined, the inherent complexity of these large systems places certain restrictions on data interpretation. Unlike small molecule studies, potential surfaces are not well understood for transition metal complexes of the type we are examining here. Conclusions drawn from ultrafast measurements must therefore rely heavily on an understanding of the compound's electronic structure derived from both static and longer time scale spectroscopic studies. Had the more extensive characterization not been carried out in the present case, interpretation of femtosecond timeresolved data on these compounds would have proceeded from an incorrect assignment of the Franck-Condon configuration. We therefore believe that careful spectroscopic characterization of metal complexes using more well-established techniques must continue to play an important role as studies of the ultrafast spectroscopy of transition metal complexes are pursued.

Acknowledgment. The authors are indebted to Dr. Heinz Frei of the Physical Biosciences Division of the Lawrence Berkeley National Laboratory for providing access to his infrared spectrometer and for numerous helpful discussions. The authors also thank Hendrik Visser for collaborating in spectroelectrochemical infrared experiments, as well as helpful discussions, Mary F. J. Talbot for assistance in obtaining emission data (both of Prof. K. Sauer's lab), and Dr. James P. Kirby for help in acquiring the nanosecond absorption data. This research was supported by the U.S. Department of Energy, Office of Basic Energy Sciences, Division of Chemical Sciences (Grant 
No. DE-FG03-96ER14665), the American Chemical Society Petroleum Research Fund (Grant No. 31016-G6), and the Alfred P. Sloan Foundation.

Supporting Information Available: A table of predicted bands for the excited-state infrared absorption difference spectra (Table $\mathrm{S} 1$ ), a plot of $\ln k_{\mathrm{nr}}$ vs $E_{0}$ illustrating energy gap law behavior (Figure S1), and spectroelectrochemical data for [Ru$\left.(\mathrm{dmb})_{3}\right]^{2+}$ (Figure S2) are available. This material is available free of charge via the Internet at http://pubs.acs.org.

\section{References and Notes}

(1) Juris, A.; Balzani, V.; Barigelletti, F.; Campagna, S.; Belser, P.; Von Zelewsky, A. Coord. Chem. Rev. 1988, 84, 85-277.

(2) Barigelletti, F.; Flamigni, L.; Balzani, V.; Collin, J. P.; Sauvage, J. P.; Sour, A.; Constable, E. C.; Thompson, A. Coord. Chem. Rev. 1994, $132,209-214$.

(3) Balzani, V.; Juris, A.; Venturi, M.; Campagna, S.; Serroni, S. Chem. Rev. 1996, 96, 759-833.

(4) O'Reagan, B.; Grätzel, M. Nature 1991, 353, 737-740.

(5) Nazeeruddin, M. K.; Kay, A.; Rodicio, I.; Humphry-Baker, R.; Müller, E.; Liska, P.; Vlachopoulos, N.; Grätzel, M. J. Am. Chem. Soc. 1993, 115, 6382-6390.

(6) Cao, F.; Oskam, G.; Meyer, G. J.; Searson, P. C. J. Phys. Chem. 1996, 100, 17021-17027.

(7) Argazzi, R.; Bignozzi, C. A.; Heimer, T. A.; Castellano, F. N.; Meyer, G. J. J. Phys. Chem. B 1997, 101, 2591-2597.

(8) Cook, M. J.; Lewis, A. P.; McAuliffe, G. S. G.; Skarda, V.; Thomson, A. J.; Glasper, J. L.; Robbins, D. J. J. Chem. Soc., Perkin Trans. 2 1984, 1293-1301.

(9) Cook, M. J.; Lewis, A. P.; McAuliffe, G. S. G.; Skarda, V.; Thomson, A. J.; Glasper, J. L.; Robbins, D. J. J. Chem. Soc., Perkin Trans. 2 1984, 1303-1307.

(10) Wacholtz, W. F.; Auerbach, R. A.; Schmehl, R. H. Inorg. Chem. 1986, 25, 227-234. 531.

(11) Mabrouk, P. A.; Wrighton, M. S. Inorg. Chem. 1986, 25, 526-

(12) Jones, W. E., Jr.; Smith, R. A.; Abramo, M. T.; Williams, M. D.; Van Houten, J. Inorg. Chem. 1989, 28, 2281-2285.

(13) Furue, M.; Maruyama, K.; Oguni, T.; Naiki, M.; Kamachi, M. Inorg. Chem. 1992, 31, 3792-3795.

(14) Kalyanasundaram, K.; Nazeeruddin, M. K. Chem. Phys. Lett. 1992 $193,292-297$.

(15) Kalyanasundaram, K.; Nazeeruddin, M. K.; Gratzel, M.; Viscardi, G.; Savarino, P.; Barni, E. Inorg. Chim. Acta 1992, 200, 831-839.

(16) Strouse, G. F.; Anderson, P. A.; Schoonover, J. R.; Meyer, T. J.; Keene, F. R. Inorg. Chem. 1992, 31, 3004-3006.

(17) Anderson, P. A.; Strouse, G. F.; Treadway, J. A.; Keene, F. R.; Meyer, T. J. Inorg. Chem. 1994, 33, 3863-3864.

(18) Anderson, P. A.; Deacon, G. B.; Haarmann, K. H.; Keene, F. R.; Meyer, T. J.; Reitsma, D. A.; Skelton, B. W.; Strouse, G. F.; Thomas, N. C.; Treadway, J. A.; White, A. H. Inorg. Chem. 1995, 34, 6145-6157.

(19) Treadway, J. A.; Meyer, T. J. Inorg. Chem. 1999, 38, 2267-2278.

(20) Bradley, P. G.; Kress, N.; Hornberger, B. A.; Dallinger, R. F.; Woodruff, W. H. J. Am. Chem. Soc. 1981, 103, 7441-7446.

(21) McClanahan, S. F.; Dallinger, R. F.; Holler, F. J.; Kincaid, J. R. J. Am. Chem. Soc. 1985, 107, 4853-4860.

(22) Cooley, L. F.; Bergquist, P.; Kelley, D. F. J. Am. Chem. Soc. 1990 , $112,2612-2617$.

(23) Yabe, T.; Orman, L. K.; Anderson, D. R.; Yu, S.-C.; Xu, X.; Hopkins, J. B. J. Phys. Chem. 1990, 94, 7128-7132.

(24) Omberg, K. M.; Schoonover, J. R.; Treadway, J. A.; Leasure, R. M.; Dyer, R. B.; Meyer, T. J. J. Am. Chem. Soc. 1997, 119, 7013-7018.
(25) Damrauer, N. H.; Cerullo, G.; Yeh, A.; Boussie, T. R.; Shank, C. V.; McCusker, J. K. Science 1997, 275, 54-57.

(26) Ellingson, R. J.; Asbury, J. B.; Ferrere, S.; Ghosh, H. N.; Sprague, J. R.; Lian, T. Q.; Nozik, A. J. J. Phys. Chem. B 1998, 102, 6455-6458.

(27) Rehm, J. M.; McLendon, G. L.; Nagasawa, Y.; Yoshihara, K.;

Moser, J.; Grätzel, M. J. Phys. Chem. 1996, 100, 9577-9578.

(28) Tachibana, Y.; Moser, J. E.; Gratzel, M.; Klug, D. R.; Durrant, J. R. J. Phys. Chem. 1996, 100, 20056-20062.

(29) Hannappel, T.; Burfeindt, B.; Storck, W.; Willig, F. J. Phys. Chem. B 1997, 101, 6799-6802.

(30) Evans, I. P.; Spencer, A.; Wilkinson, G. J. Chem. Soc., Dalton Trans. 1973, 204-209.

(31) Damrauer, N. H.; Boussie, T. R.; Devenney, M.; McCusker, J. K. J. Am. Chem. Soc. 1997, 119, 8253-8268.

(32) Slattery, S. J.; Gokaldas, N.; Mick, T.; Goldsby, K. A. Inorg. Chem. 1994, 33, 3621-3624.

(33) Claude, J. P. Photophysics of Polypyridyl Complexes of Ru(II), Os(II), and Re(I); Ph.D. Thesis, University of North Carolina at Chapel Hill, 1995; p 191

(34) Claude, J. P.; Meyer, T. J. J. Phys. Chem. 1995, 99, 51-54.

(35) Johnson, S. R.; Westmoreland, T. D.; Caspar, J. V.; Barqawi, K.

R.; Meyer, T. J. Inorg. Chem. 1988, 27, 3195-3200.

(36) Sun, H.; Frei, H. J. Phys. Chem. B 1997, 101, 205-209.

(37) Kirchhoff, J. R. Curr. Sep. 1997, 16, 11-14.

(38) Visser, H.; Curtright, A. E.; McCusker, J. K.; Sauer, K. Manuscript in preparation.

(39) Bullock, J. P.; Boyd, D. C.; Mann, K. R. Inorg. Chem. 1987, 26, 3084-3086.

(40) Krejcik, M.; Danek, M.; Hartl, F. J. Electroanal. Chem. 1991, 317 , $179-187$.

(41) Caspar, J. V.; Meyer, T. J. Inorg. Chem. 1983, 22, 2444-2453.

(42) Caspar, J. V.; Meyer, T. J. J. Am. Chem. Soc. 1983, 105, 55835590 .

(43) Barqawi, K. R.; Murtaza, Z.; Meyer, T. J. J. Phys. Chem. 1991, $95,47-50$

(44) Chen, P. Y.; Meyer, T. J. Chem. Rev. 1998, 98, 1439-1477.

(45) Creutz, C.; Chou, M.; Netzel, T. L.; Okumura, M.; Sutin, N. J. Am. Chem. Soc. 1980, 102, 1309-1319.

(46) Braterman, P. S.; Song, J. I.; Peacock, R. D. Inorg. Chem. 1992, $31,555-559$

(47) Braterman, P. S.; Song, J. I.; Peacock, R. D. Spectrosc. Acta A 1992, 48, 899-903.

(48) Nazeeruddin, M. K.; Zakerruddin, S. M.; Kalyanasundaram, K. J. Phys. Chem. 1993, 97, 9607-9612.

(49) Schoonover, J. R.; Bignozzi, C. A.; Meyer, T. J. Coord. Chem. Rev. 1997, 165, 239-266.

(50) Chen, P. Y.; Palmer, R. A. Appl. Spectrosc. 1997, 51, 580-583.

(51) Chen, P. Y.; Omberg, K. M.; Kavaliunas, D. A.; Treadway, J. A.; Palmer, R. A.; Meyer, T. J. Inorg. Chem. 1997, 36, 954+.

(52) Chen, P. Y.; Palmer, R. A.; Meyer, T. J. J. Phys. Chem. A 1998, $102,3042-3047$

(53) Omberg, K. M.; Smith, G. D.; Kavaliunas, D. A.; Chen, P. Y.; Treadway, J. A.; Schoonover, J. R.; Palmer, R. A.; Meyer, T. J. Inorg. Chem. 1999, 38, 951-956.

(54) Omberg, K. M.; Schoonover, J. R.; Bernhard, S.; Moss, J. A.; Treadway, J. A.; Kober, E. M.; Dyer, R. B.; Meyer, T. J. Inorg. Chem. 1998, 37, 3505-3508.

(55) Mallick, P. K.; Danzer, G. D.; Strommen, D. P.; Kincaid, J. R. J. Phys. Chem. 1988, 92, 5628-5634.

(56) Strommen, D. P.; Mallick, P. K.; Danzer, G. D.; Lumpkin, R. S.; Kincaid, J. R. J. Phys. Chem. 1990, 94, 1357-1366.

(57) Lever, A. B. P. Inorg. Chem. 1990, 29, 1271-1285.

(58) Juris, A.; Campagna, S.; Balzani, V.; Gremaud, G.; von Zelewsky, A. Inorg. Chem. 1988, 27, 3652-3655.

(59) Vlcek, A. A.; Dodsworth, E. S.; Pieto, W., J.; Lever, A. B. P. Inorg. Chem. 1995, 34, 1906-1913. 